\title{
Anatomical and Functional Outcomes following a Precise, Graded, Dorsal Laceration Spinal Cord Injury in C57BL/6 Mice
}

\author{
Rachel L. Hill, ${ }^{1,3}$ Yi Ping Zhang, ${ }^{2,3}$ Darlene A. Burke, ${ }^{2,3}$ William H. DeVries, ${ }^{3}$ Yongjie Zhang, ${ }^{2,3,4}$ \\ David S.K. Magnuson, ${ }^{1,2,3}$ Scott R. Whittemore, ${ }^{1,2,3}$ and Christopher B. Shields ${ }^{1,2,3}$
}

\begin{abstract}
To study the pathophysiology of spinal cord injury (SCI), we used the LISA-Vibraknife to generate a precise and reproducible dorsal laceration SCI in the mouse. The surgical procedure involved a T9 laminectomy, dural resection, and a spinal cord laceration to a precisely controlled depth. Four dorsal hemisection injuries with lesion depths of $0.5,0.8,1.1$, and $1.4 \mathrm{~mm}$, as well as normal, sham (laminectomy and dural removal only), and transection controls were examined. Assessments including the Basso Mouse Scale (BMS), footprint analysis, beam walk, toe spread reflex, Hargreaves' test, and transcranial magnetic motor-evoked potential (tcMMEP) analysis were performed to assess motor, sensorimotor, and sensory function. These outcome measures demonstrated significant increases in functional deficits as the depth of the lesion increased, and significant behavioral recovery was observed in the groups over time. Quantitative histological examination showed significant differences between the injury groups and insignificant lesion depth variance within each of the groups. Statistically significant differences were additionally found in the amount of ventral spared tissue at the lesion site between the injury groups. This novel, graded, reproducible laceration SCI model can be used in future studies to look more closely at underlying mechanisms that lead to functional deficits following SCI, as well as to determine the efficacy of therapeutic intervention strategies in the injury and recovery processes following SCI.
\end{abstract}

Key words: behavioral assessments; locomotor function; models of injury; recovery; traumatic spinal cord injury

\section{Introduction}

A NIMAL MODELS OF EXPERIMENTAL SCI are used to assess the wide array of pathological results associated with this type of traumatic central nervous system injury. The development of mouse models of SCI can further increase our potential to understand basic mechanisms behind both the initial insult and subsequent recovery. A variety of injury models have been used to investigate SCI, including compressive, contusive, and laceration/transection models. Many of these models were first developed and characterized in the rat (Allen, 1911; Beattie et al., 1988; Fehlings and Tator, 1988; Scheff et al., 2003; Stokes, 1992; Taoka and Okajima, 1998; Wrathall et al., 1985; Zhang et al., 2004), and many have been modified for use in the mouse. It is widely accepted that rats and mice exhibit very different responses to SCI (Inman et al.,
2002; Inman and Steward, 2003a; Kuhn and Wrathall, 1998; Ma et al., 2001; Sroga et al., 2003; Zhang et al., 1996). The development of several mouse SCI models (Inman and Steward, 2003b; Jacob et al., 2001; Jakeman et al., 2000; Joshi and Fehlings, 2002a,b; Kuhn and Wrathall, 1998; Plemel et al., 2008; Seitz et al., 2002; Seki et al., 2002) has allowed for further investigation into the pathology of SCI. Concerns with existing mouse SCI models include high strain variability (Basso et al., 2006; Inman et al., 2002), injury inconsistency, and decreased clinical relevance due to differences in histological injury profiles between mice and other mammals (Balantine, 1978; Blight, 1983; Blight and Decrescito, 1986; Bresnahan et al., 1976; Bunge et al., 1993; Fujiki et al., 1996; Inman and Steward, 2003a; Jakeman et al., 2000; Kakulas, 1999; Kuhn and Wrathall, 1998; Ma et al., 2001; Noble and Wrathall, 1985; Steward et al., 1999; Zhang et al., 1996). However, the benefits

Departments of ${ }^{1}$ Anatomical Sciences and Neurobiology and ${ }^{2}$ Neurological Surgery, and the ${ }^{3}$ Kentucky Spinal Cord Injury Research Center, University of Louisville, Louisville, Kentucky.

Department of ${ }^{4}$ Human Anatomy, Histology, and Embryology, Nanjing Medical University, Jiangsu Province, China. 
of using transgenic and knockout mice for SCI studies (Steward et al., 1999) outweigh these concerns. While the variability in strain responses to SCI cannot be eliminated, it does offer unique opportunities to examine how underlying genetic differences impact the injury pathology (Basso et al., 2006; Inman et al., 2002).

The purpose of this study was to develop a graded, dorsal laceration SCI in the mouse and to use specific outcome measures to identify the recovery profiles of sensory, sensorimotor, and motor deficits for each level of injury severity. Previous studies on mouse contusion and compression SCI have shown that the lesion severity and the extent of behavioral deficits are correlated (Farooque, 2000; Kuhn and Wrathall, 1998; Ma et al., 2001; Seki et al., 2002). In these studies, mild, moderate, and severe injuries resulted in both histological and functional deficits. In our study, we hypothesized that $0.3-\mathrm{mm}$ incremental laceration lesions would result in graded histological and functional deficits. We anticipated that the $0.5-\mathrm{mm}$ lesion depth would eliminate the ascending fibers in the fasciculus gracilis and the corticospinal tract (CST), thus having minimal effect on hindlimb function. The 0.8 -mm injury was anticipated to cut through the rubrospinal tracts, the dorsolateral CST (Steward et al., 2004), and Clarke's nucleus (lamina X). Damage to the dorsolateral funiculus has been previously shown in rat and cat models of SCI to contribute to behavioral deficits (Eidelberg et al., 1986; Fehlings and Tator, 1995; Loy et al., 2002a,b; Schucht et al., 2002; Whishaw et al., 1992). The 1.1- and 1.4-mm lesions were anticipated to disrupt ascending and descending fiber tracts in the ventral and medial lateral funiculi. Previous studies have shown that several of these white matter fiber tracts are important for locomotor control, and that damage to these tracts produces significant functional deficits, and sparing correlated with remaining hindlimb function (Fehlings and Tator, 1995; Loy et al., 2002b; Schucht et al., 2002). We included the near-complete transection to investigate a minimal level of ventral white matter sparing for return of any noticeable recovery of function (Blight, 1983).
Animals from the lesioned groups show distinct histological measures as well as distinct profiles of functional behavioral recovery. Therefore, producing a graded SCI in mice using different laceration depths is an acceptable method for assessing graded injury outcomes. The other models of graded SCI that have been used, such as contusion (Ma et al., 2001; Seki et al., 2002), compression (Farooque, 2000), and weight-drop (Kuhn and Wrathall, 1998), lack the mechanical displacement accuracy of the LISA-Vibraknife and the superior vertebral stabilization utilized in this study.

A variety of biological mechanisms have been proposed to facilitate recovery, such as neuroprotection, remyelination, axon regeneration, and plasticity (Ramer et al., 2005; Schwab et al., 2006). The contribution of naturally occurring mechanisms to recovery is often unaccounted for or overlooked. Our results show distinct and significant sensory and motor functional recovery in the absence of treatment, while additionally confirming that the behavioral and histological parameters of the injury groups are significantly different from one another. A detailed understanding of the relationship between increasing laceration depths and the observed temporal recovery profiles of mice recovering naturally provides further insight into the evolving pathophysiology associated with functional plasticity of C57BL/6 mice.

\section{Materials and Methods}

\section{Experimental groups}

A total of 121 young adult (10-15 weeks of age, 20-24 g; Jackson Laboratories, Bar Harbor, ME) C57BL/6 female mice were used for these experiments (Table 1$)$. The animals were randomly divided into seven groups: normal, sham $(0.0 \mathrm{~mm})$, mild $(0.5 \mathrm{~mm})$, moderate $(0.8 \mathrm{~mm})$, severe $(1.1 \mathrm{~mm})$, nearcomplete $(1.4 \mathrm{~mm})$, and complete transection $(\mathrm{Tx} ; 1.6 \mathrm{~mm})$. Thirty-seven mice were used for sciatic nerve tracing and were allowed to survive for 3-5 additional days, and the 21 mice used for the CST tracing were allowed to survive for an additional 14-15 days post-injection. All mice underwent

TABLe 1. EXPERIMENTAL Groups

\begin{tabular}{|c|c|c|c|c|}
\hline & & \multicolumn{3}{|c|}{ Lesion and spared tissue } \\
\hline \multicolumn{2}{|c|}{ Experimental groups } & \multicolumn{2}{|c|}{ Injury depth (mm) } & \multirow[b]{2}{*}{ Ventral spared tissue } \\
\hline Desired lesion depth (mm) & $N$ (no. of mice) & Desired & Actual & \\
\hline 0 (normal) & 12 & 0 & $\mathrm{n} / \mathrm{a}$ & $\mathrm{n} / \mathrm{a}$ \\
\hline 0 (sham) & 7 & 0 & $\mathrm{n} / \mathrm{a}$ & $\mathrm{n} / \mathrm{a}$ \\
\hline 0.5 & 21 & 0.5 & $0.43 \pm 0.09^{\mathrm{a}, \mathrm{b}}$ & $1.21 \pm 0.11^{\mathrm{b}}$ \\
\hline 0.8 & 22 & 0.8 & $0.70 \pm 0.09^{\mathrm{a}, \mathrm{b}}$ & $0.92 \pm 0.11^{\mathrm{a}}$ \\
\hline 1.1 & 23 & 1.1 & $0.96 \pm 0.10^{\mathrm{a}, \mathrm{b}}$ & $0.62 \pm 0.11^{\mathrm{b}}$ \\
\hline 1.4 & 26 & 1.4 & $1.33 \pm 0.11^{\mathrm{b}}$ & $0.24 \pm 0.07^{\mathrm{b}}$ \\
\hline 1.6 & 10 & 1.6 & 1.6 & 0 \\
\hline
\end{tabular}

Experimental groups: The lesion depth for each group, the number of mice in each group, and the number of mice that died in that group (mortality) during the course of the study. The total number of mice used in this study was 121; however, 20 mice died during the course of the study, a mortality rate of $17 \%$.

Lesion depth and spared tissue quantification: The desired displacement values were significantly higher than the actual lesion depths for groups 3-5, but not for group 6 (one sample $t$-test; ${ }^{\mathrm{a}} p<0.01$ ). The power of this analysis to detect a true significant difference between the displacement of the LISA-Vibraknife device and the anatomical depths of each injury group was $\geq 64.3 \%$. The actual lesion depths of the injury groups were significantly different from each other $\left({ }^{b} p<0.001\right)$. The power of this analysis to detect a true significant difference between the 1.1- and 1.4-mm groups was $89.1 \%$; the power of the significance detected between the other injury groups was equal to $100 \%$. There was a significant difference in the amount of ventral spared tissue between the lesion groups $\left({ }^{b} p<0.001\right)$. Ventral spared tissue area $(\%)$ significantly correlated with lesion depth $\left(r^{2}=0.99\right)$. 
behavioral assessments at $1,3,7,14,28$, and 42 days postinjury (dpi).

\section{Surgical procedures and postoperative care}

To ensure injury consistency, we implemented two novel techniques to increase injury precision and reproducibility. The first of these was a spinal column stabilizer for the mouse (Fig. 1), and the second was the Louisville Injury Systems Apparatus with the Vibraknife attachment (LISA-Vibraknife; Louisville, KY) (Sivasankaran et al., 2004; Zhang et al., 2004; Zhang et al., 2007a), which can control the lesion depth with high accuracy. Mice were anesthetized with an intraperitoneal injection of Avertin ${ }^{\circledR}$ (1.3\% tribromoethanol and 0.8\% tert-amyl alcohol; $15-20 \mu \mathrm{L} / \mathrm{g}$ ). The hair on the animal's back was shaved and the area was cleaned with $70 \%$ ethanol. A small $(1.0-1.5 \mathrm{~cm})$ midline incision was made over the thoracic vertebrae. The animal was situated within a U-shaped metal channel (Fig. 1B) with minimal separation of the paravertebral muscles. The stainless steel arms of the stabilizer (Fig. 1A) were inserted under the vertebral facets of the 10th thoracic vertebra (T10) to prevent movement during the laceration procedure. The edge of the T9 lamina adjacent to T10 was trimmed along with the ligamentum flavum to expose the spinal cord. A puncture using an angled sterile 32-gauge needle allowed for dural and arachnoid resection across the laceration site with microscissors. Using the LISA-Vibraknife, the mice received partial dorsal lacerations of varying depths:
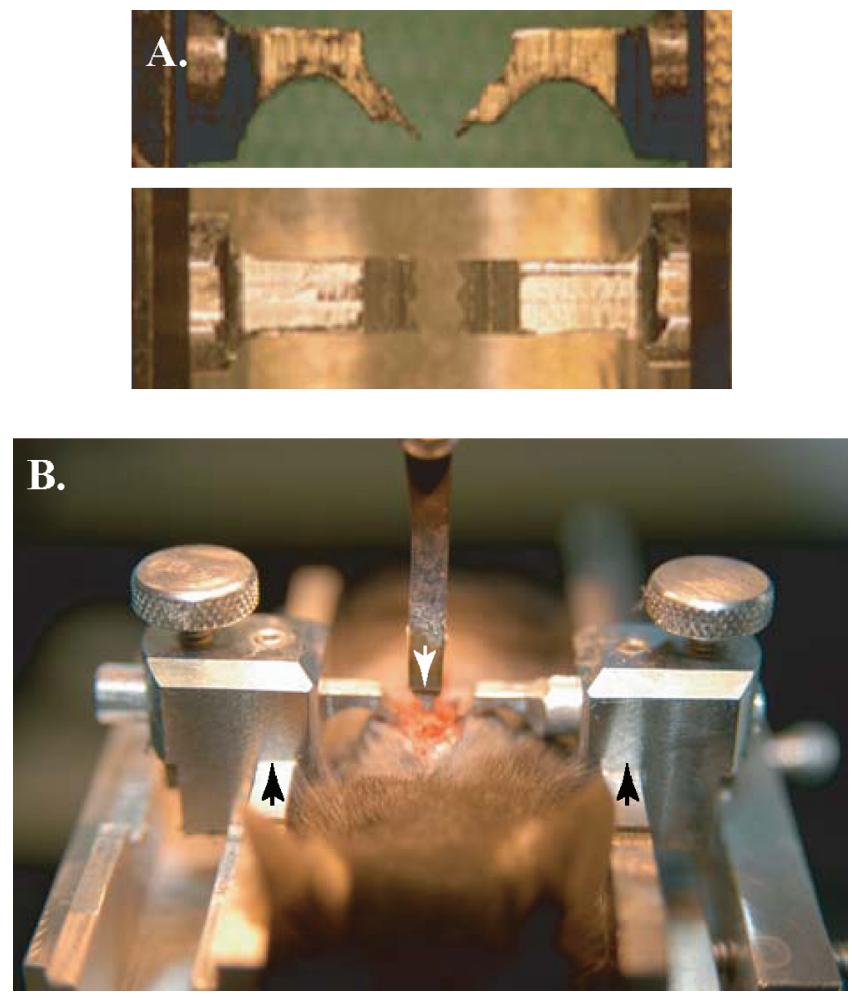

FIG. 1. Mouse stabilizer set-up for LISA-Vibraknife lesion. (A) Bilateral spinal column stabilizers; lateral view (top panel), ventral view (bottom panel). (B) The mouse is placed in a U-shaped metal channel (arrows on the right and left), and the blade (arrow in the middle) is positioned over the spinal cord surface under a dissecting microscope.
$0.5,0.8,1.1$, or $1.4 \mathrm{~mm}( \pm 0.008 \mathrm{~mm})$. The platform on which the mice were placed was raised until the 1.2-mm-wide blade of the LISA-Vibraknife (Fig. 1B) contacted the dorsal surface of the spinal cord (considered zero depth). Placement was confirmed using a dissecting microscope prior to immersing the tip of the blade and the dorsal surface in Hank's balanced salt solution (Invitrogen; Carlsbad, CA). To prevent the oscillating blade from contacting the vertebral body, complete transection $(1.6 \mathrm{~mm})$ was produced using a modified-angle scalpel blade to cut the ventral cord tissue following a 1.4mm-deep laceration. Following each injury, before removal of the LISA-Vibraknife blade, the spinal cord was assessed for deformation of the tissue to ensure the laceration did not cause an additional contusion to the lesion. The musculature was sutured with 10-0 suture and the skin was closed with 9-mm metal suture clips (Becton Dickinson, Sparks, MD). To compare our method with the more routine manual microscissor laceration, a dorsal cut was made using $2.5-\mathrm{mm}$ microscissors (Fine Science Tools, Foster City, CA) marked at $0.8 \mathrm{~mm}$ for depth control. Each animal received $2 \mathrm{~mL}$ of saline (subcutaneous injection) immediately post-injury and recovered for $24 \mathrm{~h}$ in a designated recovery room. Food and water were available ad libitum and cage temperatures were maintained at the animals' body temperature $\left(37-38^{\circ} \mathrm{C}\right)$ by placing them on heating pads overnight. The animals were housed in ventilated cages with fewer than 5 mice/cage. Animals that received greater than $0.8 \mathrm{~mm}$ laceration injuries received manual bladder expression, soft food for 1 week, additional subcutaneous saline injections as needed, and remained in partially heated cages up to 4 weeks following surgery.

\section{Histologic assessment}

At 6-8 weeks post-injury, the mice were given an overdose of sodium pentobarbital $(100 \mathrm{mg} / \mathrm{kg}$ of Nembutal; Abbott Laboratories; North Chicago, IL) and perfused transcardially, first with $5 \mathrm{~mL}$ of phosphate buffered saline (PBS; $0.01 \mathrm{M}, \mathrm{pH}$ 7.4 ), then with $30 \mathrm{~mL}$ of cold $4 \%$ parformaldehyde (PFA) in PBS. A 10-12 mm thoracic spinal cord segment spanning the lesion's epicenter was carefully dissected and stored at $4{ }^{\circ} \mathrm{C}$ in $30 \%$ sucrose in PBS. All tissue samples were embedded in tissue freezing medium (Triangle Biomedical Sciences, Durham, NC) and 20- $\mu$ m sagittal sections were cut using a Leica cryostat (Leica Microsystems, Bannockburn, IL), and then mounted on Colorfrost Plus electrostatically charged microscope slides (Fisher Scientific, Fair Lawn, NJ). Sections were stained with cresyl violet and eosin, dehydrated, cleared, and cover-slipped using Permount (Fisher Scientific).

To standardize the analysis of spared tissue and lesion depth, we measured mid-sagittal sections that included a profile of the central canal. Of the sections measured, the sections with the largest lesion and smallest spared tissue values were used for analysis. Spared tissue was measured from the edge of laceration, based on a qualitative assessment of the laceration injury, to the ventral surface of the cord. The diameter measurements were obtained from the same section, within $1 \mathrm{~mm}$ rostral to the lesion. By measuring the diameter rostral to the lesion, we are ensuring maximal diameter (closest to normal); measurements caudal to the lesion were smaller due to degeneration of axons caused by the lesion. The spared tissue area measurements obtained from the cross-sectional sections were based on both the sagittal 
measurements and a hypothetical graded lesion depth (0.1$1.1 \mathrm{~mm}$ post-fixation). Based on fresh tissue measurements, we found that spinal cords of mice have an average diameter of $1.6 \mathrm{~mm}$, and after perfusion fixation with $4 \%$ PFA, the spinal cord shrinks to an average diameter of $1.18 \pm 0.13 \mathrm{~mm}$. This reduction in spinal cord diameter due to fixation was corrected in the calculations for lesion depth and ventral spared tissue. This correction was made by determining the ratio of pre- to post-fixed cord diameter: $1.60 / 1.18$, then by multiplying each sagittally-measured lesion depth by that ratio. Digital photomicrographs of the sagittal sections were captured on a Nikon TE-2000 (Nikon, Inc., Melville, NY) microscope with imaging software. All measurements were determined using the Neurolucida system (MicroBrightField Inc., Colchester, VT).

Anterograde tracing of the corticospinal tract (CST) was performed 6 weeks after SCI by injection of $10 \%$ Texas Red conjugated biotinylated dextran amine (TR-BDA; Vector Laboratories, Burlingame, CA) into the sensorimotor cortex using a glass micropipette. To prepare the animals for the injections, the mice were anesthetized with ketamine + xylazine $(0.2 \mathrm{~mL}+0.1 \mathrm{~mL} / 20 \mathrm{~g}$ body weight $)$, shaved, and cleaned with $70 \%$ ethanol, then stabilized in a stereotactic frame. The sensorimotor cortex was exposed bilaterally by removing small sections of the skull. TR-BDA was then injected $(0.5 \mu \mathrm{L} /$ site $)$ into the cortex using a $40-\mu \mathrm{m}$-outerdiameter bevel-tipped glass micropipette attached to a Picoinjector (World Precision Instruments Inc., Sarasota, FL). The stereotactic coordinates for the injections were as follows: from the bregma $-0.5 \mathrm{~mm}$ rostral-caudal $(\mathrm{RC}) / 1.0 \mathrm{~mm}$ mediolateral (ML) (Ghasemlou et al., 2005); $0.5 \mathrm{~mm} \mathrm{RC} / 1.0 \mathrm{~mm}$ ML. Two injections were made bilaterally at a depth of $0.7 \mathrm{~mm}$ from the cortical surface at each site. Following each injection, the micropipette was allowed to remain at the site for $3 \mathrm{~min}$ before withdrawal of the tip from the cortex. The mice were allowed to survive for 14-15 days post-injection. For detection of the TR-BDA anterograde-labeled axons in the CST, sagittal sections $(20 \mu \mathrm{m})$ through the laceration injury site were airdried and then cover-slipped using the ProLong Antifade kit (Invitrogen).

Anterograde tracing of ascending dorsal column axons was performed 6 weeks after SCI by bilateral sciatic injections of $2 \%$ cholera toxin B (CTB) $(0.25 \mu \mathrm{L}$ each injection; Sigma, St. Louis, MO) using a 32-gauge needle. The mice were anesthetized using an IP injection of the ketamine/xylazine mix (see above). Prior to each injection, the sciatic nerve was ligated proximally to the injection site. Following each injection, the needle remained in the nerve for $4 \mathrm{~min}$ before removal, and then the sciatic nerve was lightly crushed with forceps to prevent leakage and to enhance the uptake of the CTB. The mice were then allowed to survive for 3-4 days.

For detection of the CTB anterograde labeled axons from the sciatic nerve into the dorsal columns, sagittal sections $(20 \mu \mathrm{m})$ (as described above) were washed with TBS and then rinsed with $0.25 \%$ Triton in TBS. Wash and rinse were repeated once more before applying the primary antibody (goat anti-CTB, 1:1000; List Biologicals, Campbell, CA). The primary-antibody-covered sections were then incubated in a hydration box at $4^{\circ} \mathrm{C}$ overnight. The sections were rinsed in TBS, then the secondary antibody (FITC conjugated donkey anti-goat, 1:200; Jackson ImmunoResearch, West Grove, PA) was applied and incubated for $1 \mathrm{~h}$ at room temperature. The sections were rinsed again with TBS, dehydrated, cleared, and cover-slips were mounted with Gel/Mount (Biomeda, Foster City, CA).

\section{Behavioral assessments}

All animals were subjected to a number of sensory and motor tests to establish deficits associated with each level of injury severity. The animals were tested at the following time points following injury: 1, 3, 7, 14, 28, and $42 \mathrm{dpi}$. Scoring of all behavioral measures was done by observers blinded to the injury groups.

Training. All animals received training prior to surgery. The animals were first gentled by handling for 2 days, and then acclimated to the open field for the locomotor test for four sessions. The mice were also trained on the elevated beam: each animal repeated four runs on the two smallest beams $(0.8$ and $0.4 \mathrm{~cm})$. For acclimation to the Hargreaves' test (Model 360; IITC Life Science, Woodland Hills, CA) (Hargreaves et al., 1988), the mice were allowed to remain in the acrylic glass set-up for $10 \mathrm{~min}$ before being tested. For the footprint runway training, each animal traversed the enclosed runway four times. These training procedures for the beam, runway, and Hargreaves' tests were repeated for 3 days.

Basso Mouse Scale (BMS). The BMS was used to assess open field locomotion for all injury groups. This scale has been shown to be more sensitive, reliable, and valid for assessing mouse behavior following SCI than the BBB scale designed for rats (Basso and Fisher, 2003; Basso et al., 2006; Engesser-Cesar et al., 2005). Two raters (trained at Ohio State University) blinded to the injury groups scored the mice. The BMS score ranges from 0-9 and the subscore ranges from 0-11. In order to determine the recovery of particular behavioral components of locomotion, individual attributes such as plantar stepping, coordination, and paw position were assessed using the subscore values (from the score sheet; see Basso et al., 2006 for the score sheet) for each of these components.

Footprint analysis. A footprint analysis method modified from that described by several others (De Medinacelli et al., 1982; Fiore et al., 2004; Kunkel-Bagden et al., 1993; Ma et al., 2001) was used. The animal's fore- and hindpaws were inked with dyes of blue and red, respectively, and then they traversed a narrow runway $(50 \times 4 \times 4 \mathrm{~cm})$ lined with white paper to receive a food treat in the dark box at the other end. Only mice that were scored as frequently or consistently plantar stepping were tested (BMS score $\geq 5$ for both hindlimbs).

Analysis was based on the following six parameters: (A) Step cycle. To obtain a sufficient number of consecutive steps for accurate analysis, each animal was required to provide two passes in which at least five step cycles could be analyzed. A step cycle is the distance from one pair of forelimb prints to the next, with an accompanying set of hindpaw prints. (B) Base of support (BOS). Hindlimb support was determined by measuring the distance between the centers of each hindpaw print, with the center based on the placement of the second and third toes. (C) Stride length. The length for each hindlimb step was measured between two consecutive prints for each hindpaw. Right and left sides were measured separately. (D) Stance length. The length of the stance phase of each cycle was 
measured between the forepaw and hindpaw print of each complete cycle. Right and left sides were measured separately. (E) Regularity index (RI). The degree of interlimb coordination was assessed using the RI (Hamers et al., 2001). The RI grades coordination as follows: $\mathrm{RI}=\left(\left(\mathrm{NSSP}^{*} 4\right)\right.$ / $P P)^{*} 100(\%)$, where NSSP represents the total number of step cycles and $\mathrm{PP}$ is the total number of paw placements (forepaw and hindpaw). In addition, the right-left coordination of the hindlimbs was assessed by the absolute value of the difference between the coefficients of variation $(\mathrm{CoV})$ of stride and stance lengths for the hindlimbs (Fiore et al., 2004). (F) Toe drag. For each trial the hindpaw toe drags were counted and expressed as the number of toe drags/step cycle for that trial.

Elevated gradient walking beam. Mice that showed frequent or consistent plantar stepping were evaluated using a graded series of metal beams ( $24.13 \mathrm{~cm}$ in length) of various widths: 2, 1.6, 1.2, 0.8, and $0.4 \mathrm{~cm}$ (Farooque, 2000; KunkelBagden et al., 1993; Zang and Cheema, 2003). The beams were suspended $(15 \mathrm{~cm}$ high) across a plastic tank filled with $5-6 \mathrm{~cm}$ of soft bedding. The average number of step cycles from one side of the beam to the other was 5 for normal animals (data not shown). Normal animals can easily and quickly cross the $0.4-\mathrm{cm}$ bar, while injured animals displayed varying degrees of deviation from the normal performance values for this test. The narrowest beam each mouse could traverse was recorded, along with the number of errors across four trials. Hindpaw and whole-body falls were both counted as errors. If an animal could not maintain placement of its hindpaws on the beam, or if the animal was dragging its hindquarters across the beam, this was considered failing the task, and no score was recorded for the animal. To incorporate both beam size and the number of errors in a way to establish overall task performance, we developed a scale for scoring the mice (Supplementary Table 3). Data for this test were obtained by taking the average of four trials per beam per animal.

Toe spread reflex response. A normal mouse will reflexively splay the toes of the hindpaws upon having their hindquarters elevated by lifting the tail (Kuhn and Wrathall, 1998). Each animal was tested three times and the responses of the hindpaws were documented. Toe splay reflex responses were recorded as follows, the numbers correspond to the score for the observed response: hyper-splay (4), normal splay (3), less-than-normal splay (2), clenched (no splay, but response) (1), or no response (0). The responses were all scored by the same blinded evaluator, and score assessment was based on qualitative judgments of deviation from normal. The overall score for each animal was an average of three trials for each time point tested.

Hargreaves' noxious thermal stimulus test. The mice were tested using the Hargreaves' apparatus set at 30\% intensity, with a cutoff time of $20 \mathrm{sec}$ to avoid tissue damage. The mice were tested prior to surgery and again at $1,3,7,14$, 28 , and $42 \mathrm{dpi}$. For each testing session, the mice were allowed to acclimate in the apparatus for $10 \mathrm{~min}$ prior to testing. The glass testing surface was pre-warmed to $34^{\circ} \mathrm{C}$ prior to arranging the animals in the acrylic glass chambers. For each mouse, all four paws were tested by allowing the heat source to shine on the plantar surface of the paw until the animal withdrew from the noxious thermal stimulus. After each paw was tested, a minimum of $5 \mathrm{~min}$ was allowed before testing the same paw again. This was repeated so that for each testing session all four paws for each mouse had been tested five times. The 1.6-mm (Tx) group was not included in this test because the plantar surface of the animal's hindpaws were exposed to the glass (the dorsal surface of the paws were on the glass).

\section{Electrophysiology}

All transcranial magnetic motor-evoked potential (tcMMEP) recordings were obtained from awake, nonanesthetized, restrained mice (Zhang et al., 2007b). The active electrode needle was inserted into the belly of the gastrocnemius muscle, a second reference electrode needle was inserted near the distal tendon of the gastrocnemius muscle, and a third ground electrode needle was inserted into the base of the tail. tcMMEPs were elicited using a magnetic stimulator (Cadwell Laboratories; Kennewick, WA) with a 5.0-cm doughnut-shaped coil. The center of the coil was placed at a $45^{\circ}$ angle lying on the head of the animal. A single pulse with $100 \%$ intensity was repeated three times with a 30 -sec lapse between trials bilaterally. The onset latency was measured in milliseconds (msec) and the peak-trough amplitude was measured in millivolts $(\mathrm{mV})$. Amplitude background noise was determined to be approximately 40 microvolts $(\mu \mathrm{V})$; we set the signal-to-noise ratio at four times this level $(160 \mu \mathrm{V})$. Recordings with amplitudes less than $160 \mu \mathrm{V}$ were considered noise. The latency window was established to fall between 4 and $5 \mathrm{msec}$. Baseline recordings were obtained prior to injury. All animals except the 1.6-mm (Tx) group were tested at 3, 7, 14,28 , and 42 dpi.

\section{Statistical analyses}

To determine if the injury depths were significantly different from each other, a one way-analysis of variance (ANOVA) was used. ANOVA analysis was also used to detect differences within a particular group or at a particular time. To detect significant interactions between the groups across time, a repeated measures ANOVA with post-hoc TukeyHSD $t$-tests was used. A power analysis of the observed results was performed on the group means, standard deviations, and sample sizes to determine the power of the statistical analyses to detect true significant differences between the groups. All power analysis values fell above $71.4 \%$, with the majority falling above $90 \%$ (only 16 analyses of all those done were below 90\%). A chi-square analysis was performed to detect a significant trend in the frequency of task completion for the beam walk test. We also used Pearson bivariate correlations to test the results for significant correlations. Onesample $t$-tests were run to assess lesion depth differences. The $\mathrm{CoV}$ of repeated measures for right and left stride and stance lengths was evaluated to determine right-left hindlimb coordination.

\section{Results}

\section{Anatomical assessment of the lesion and ventral spared tissue demonstrate significant differences and confirm a graded laceration model}

Anatomical and histological assessment of the lesion acutely confirmed the lesion depths (Fig. 2A). By correcting 

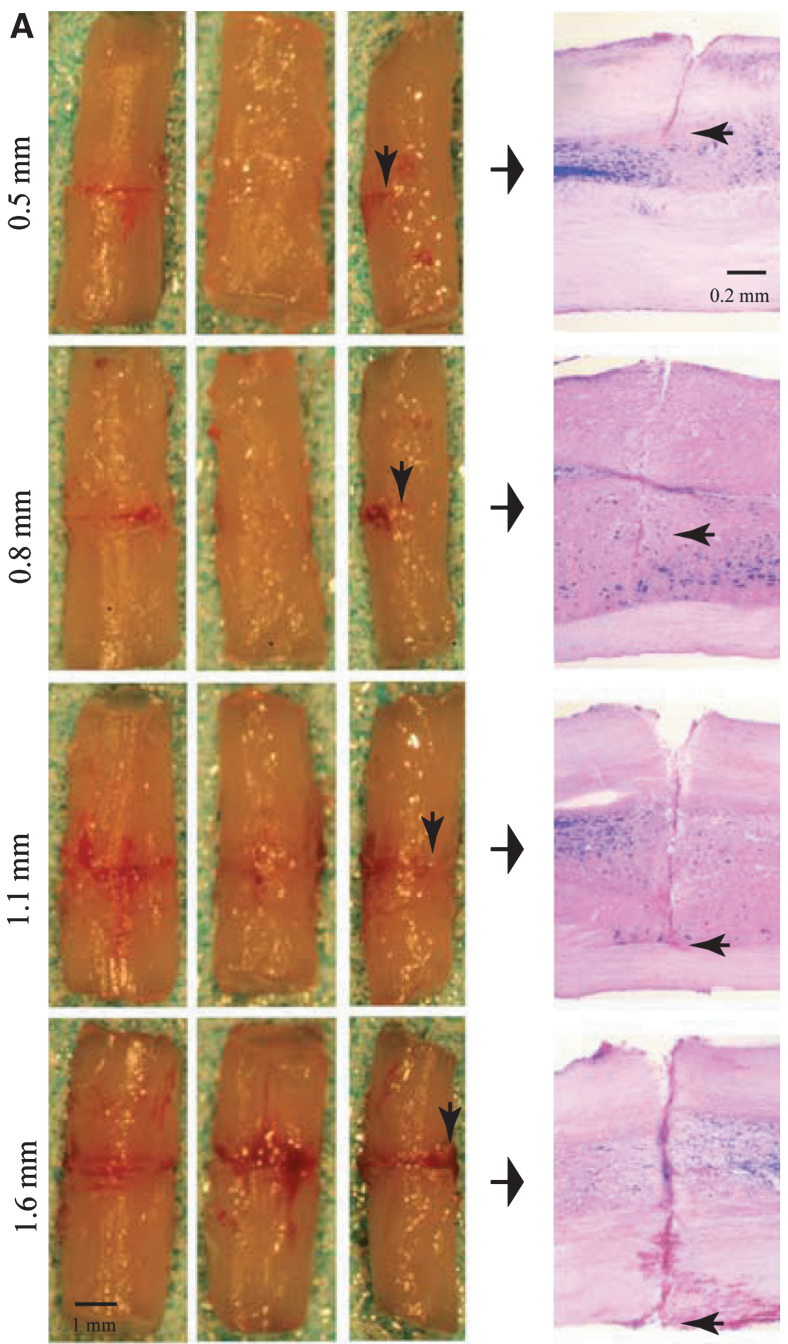

D

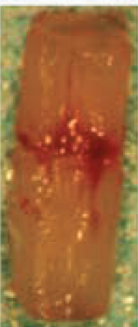

V
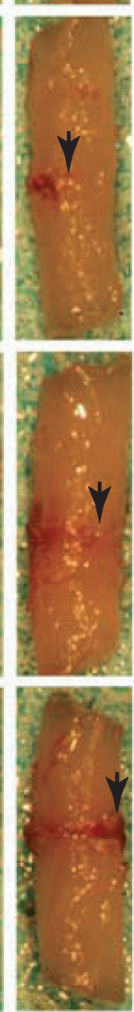

L $\rightarrow$
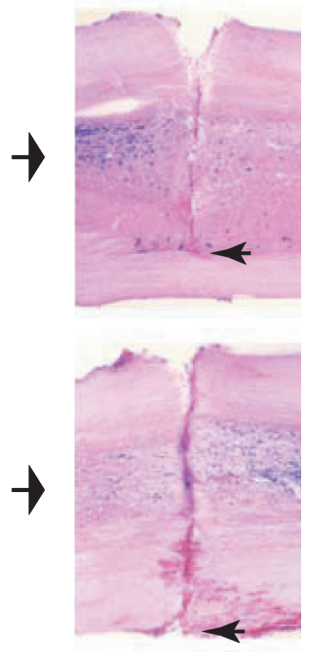

\section{B $\quad 0.5 \mathrm{~mm}$ \\ Vibraknife}
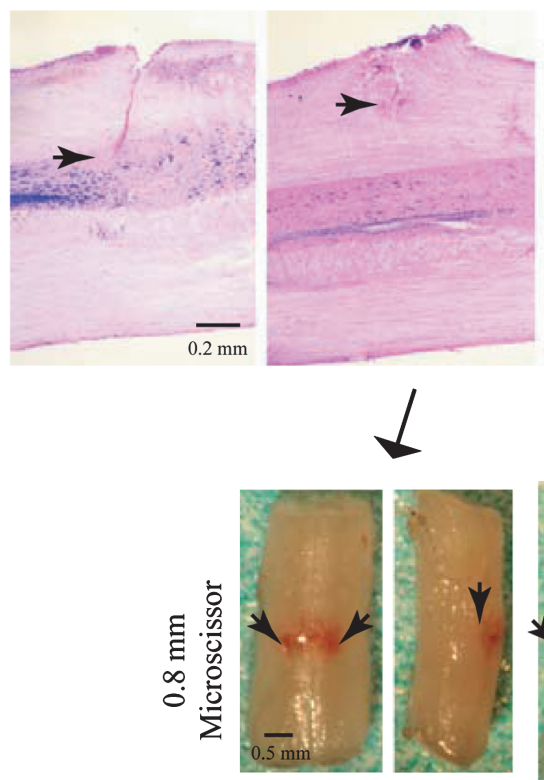

$\mathrm{D}$

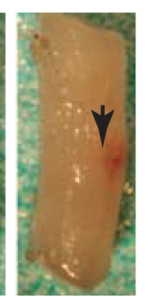

L
$0.8 \mathrm{~mm}$

Microscissor

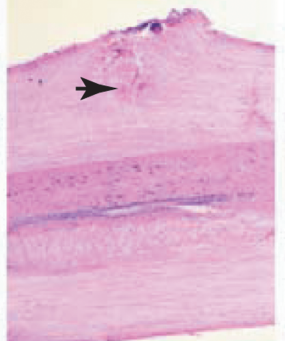

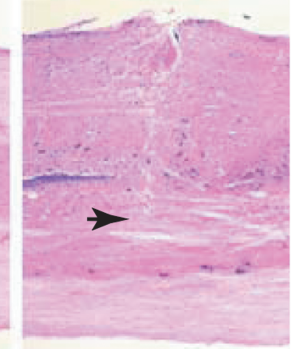
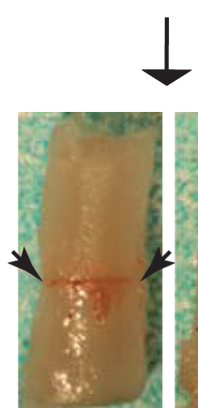

D
$0.8 \mathrm{~mm}$

Vibraknife

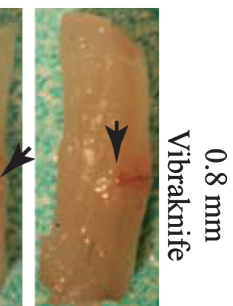

L

FIG. 2. Acute anatomical qualitative assessment of the lesion. (A) The dorsal (D), ventral (V), and lateral (L) surfaces of the spinal cord at $20 \mathrm{~min}$ following a laceration injury of $0.5 \mathrm{~mm}$ (top row), $0.8 \mathrm{~mm}$ (second row), $1.1 \mathrm{~mm}$ (third row), and $1.6 \mathrm{~mm}$ (Tx; last row). Arrows point to corresponding histological images of each lesion (last column on the right); small black arrows pinpoint the lesion depth. Note the absence of dorsal surface deformation or contusion. (B) Demonstrates the difference in the lesion depths when comparing the LISA-Vibraknife lesions to those generated by another surgeon using microscissors. The microscissor injury was supposed to generate a $0.8-\mathrm{mm}$-deep lesion; however, the microscissor lesion depth is less than the $0.5-\mathrm{mm}$ laceration injury shown in the left panel. Arrows point to images of the spinal cord following an acute microscissor injury ( $\mathrm{D}$ and $\mathrm{L}$ panels on the left), compared to a $0.8-\mathrm{mm}$ laceration injury ( $\mathrm{D}$ and $\mathrm{L}$ panels on the right).

for fixation shrinkage, we were able to assess the accuracy of the LISA-Vibraknife displacement in vivo. We compared the desired lesion depths for groups $3-6$ to the actual lesion depths and found significant differences for groups 3-5, but not for group 6 (Table 1). The actual lesion depths were significantly different across the experimental groups. There was also a significant difference in the amount of ventral spared tissue between the lesion groups (Table 1). The amount of ventrally spared tissue (percentage of cross-sectional area) significantly correlated with lesion depth $\left(r^{2}=0.99\right.$; data not shown).

A second set of animals $(n=20)$ was added to the experiment to determine the reproducibility of the injury depths. There were no significant differences in the lesion depths within any of the experimental injury groups from the first set of animals $(p>0.05)$, nor were there significant differences (as determined histologically) between the two sets of animals $(p>0.05)$. These results clearly demonstrate the precision of the device. Despite the reduced accuracy of the actual injury depth compared to our desired depth, we were still able to generate a more precise and reproducible laceration lesion than a laceration generated by a pair of microscissors (as shown histologically and anatomically in Fig. 2B).

\section{BMS scores show significant differences between the injury groups and significant locomotor recovery over time}

The normal and sham scores were never significantly different from each other, nor did they show significant changes in their scores over time (Fig. 3A). The injury groups showed significant increases in their BMS scores over the course of the 

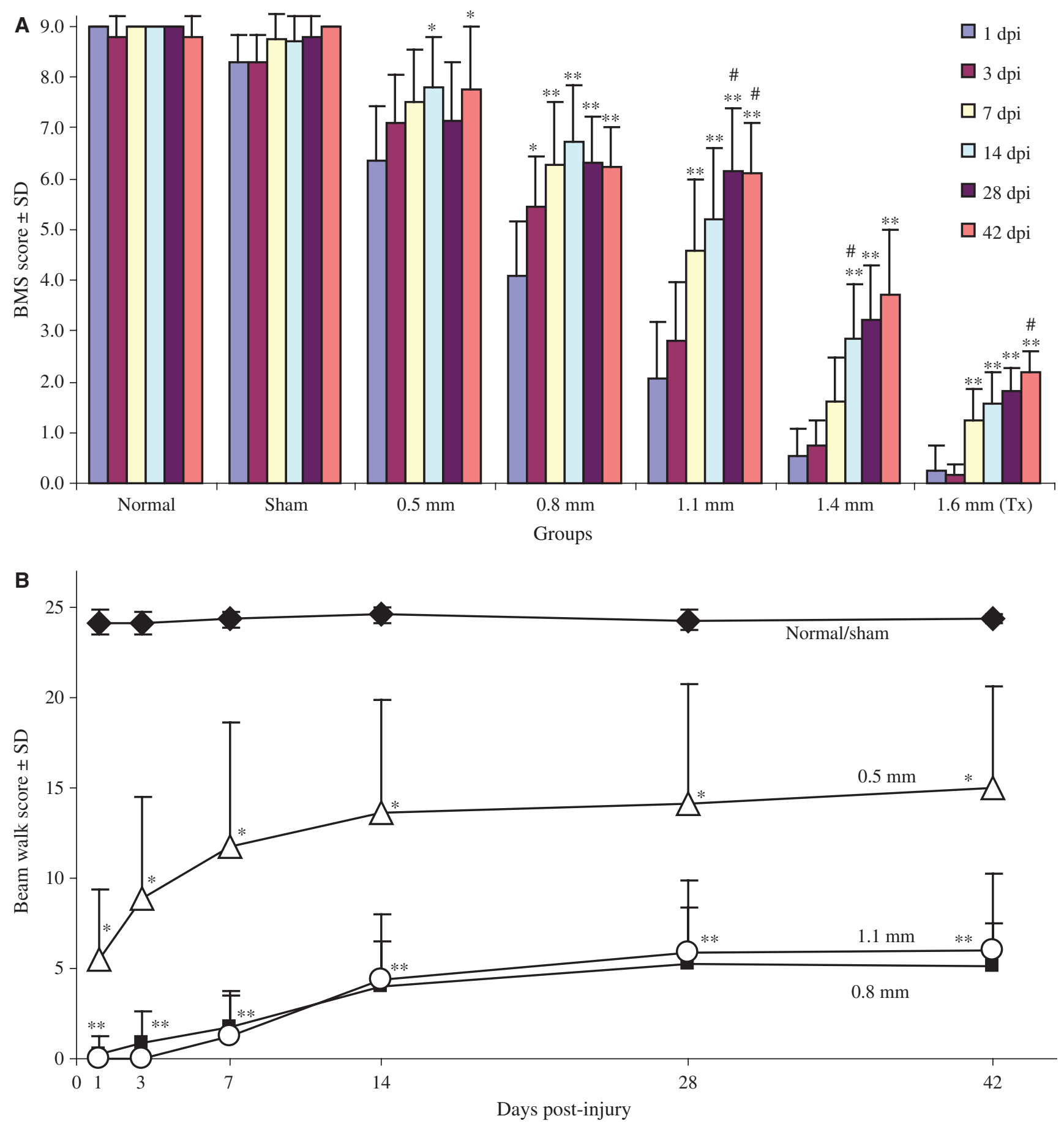

FIG. 3. BMS and beam walk scores over time. (A) BMS scores demonstrate significant improvement in over-ground locomotion behavior over time within each of the groups $\left({ }^{*} p<0.05 ;{ }^{* *} p<0.01\right)$, excluding the normal and sham groups. In the 0.5 -mm group: scores at 14 and $42 \mathrm{dpi}$ were significantly higher than the 1 -dpi scores $(p<0.05 ; \mathrm{n}=8-13)$. In the 0.8 -mm group: scores at 7, 14, 28, and $42 \mathrm{dpi}$ were significantly greater than their 1-dpi scores $(p<0.01 ; \mathrm{n}=9-14)$; the 3 -dpi scores were also significantly higher than the 1-dpi scores $(p<0.05)$. In the 1.1-mm group: scores at $7,14,28$, and $42 \mathrm{dpi}$ were significantly higher than the 1- and 3-dpi scores $(p<.001)$; the 28- and 42-dpi scores were also significantly higher than the 7 -dpi scores $(p<0.05 ; \mathrm{n}=11-14)$. For the 1.4-mm group, the scores at 42, 28, and 14 dpi were significantly higher than the 1-, 3-, and 7-dpi scores $(p<0.01 ; \mathrm{n}=9-15)$; the 14-dpi scores were significantly higher than the 7- $(p<0.05), 3-$, and 1-dpi scores $(p<0.01)$. For the 1.6-mm (Tx) group, the scores at 42, 28, 14, and $7 \mathrm{dpi}$ were significantly higher than the 1-and 3-dpi scores $(p<0.01 ; \mathrm{n}=8-10)$; the 42-dpi scores were also significantly higher than the 7-dpi scores $(p<0.01)$. (B) Beam walk. The normal/sham group scored significantly higher than the 0.5-, 0.8-, and 1.1-mm groups throughout the course of the study $(p<0.01)$. The 0.5-mm group $\left(^{*}\right)$ was significantly lower than the normal/sham group and significantly higher than the 0.8 - and $1.1-\mathrm{mm}$ groups at all time points. The 0.8 - and $1.1-\mathrm{mm}$ groups were significantly lower $\left({ }^{*}\right)$ than the normal/sham and $0.5-\mathrm{mm}$ group at all time points, but were never significantly different from each other $(p<0.01 ; \mathrm{n}=8-13)$. 
study (Fig. 3A), and were significantly different from each other injury group at certain time points (Supplementary Table 1). The terminal (42 dpi) BMS scores for all the animals showed a significant correlation with the ventral spared tissue for each injury group $\left(\mathrm{r}^{2}=0.76 ; p<0.001\right)$.

\section{BMS subscores show significant differences between the injury groups and significant recovery over time}

The normal and sham animals showed no significant change in subscores over time, nor were they ever significantly different from each other. The 0.5-, 0.8-, 1.1-mm lesioned mice showed significant improvement in their subscores over time, and were significantly different from each other at certain time points (Supplementary Table 2). The 1.4$\mathrm{mm}$ group received subscores only at $42 \mathrm{dpi}$, so we were not able to determine if there was any change over time. The 1.6$\mathrm{mm}(\mathrm{Tx})$ group never received subscores and were not included in this analysis.

\section{Elevated gradient beam walk detects deficits in balance and fine motor skills in the injury groups across time}

For the normal mice, there were significant correlations between beam size and average crossing time (data not shown; $\mathrm{r}^{2}=0.84$ ), and between beam size and error number $\left(r^{2}=0.71\right)$. For the experimental groups, there was a significant correlation between beam size and the number of errors $\left(r^{2}=0.29\right)$. The normal and sham animals were never significantly different from each other, so their scores were combined (normal/sham group, Fig. 3B). The scores for the injured mice demonstrated significant differences between the groups over the course of the study (Fig. 3B). The average beam sizes that each experimental group could successfully traverse over the course of the study are as follows: normal, $0.4 \pm 0.0$; sham, $0.4 \pm 0.1 ; 0.5 \mathrm{~mm}, 1.3 \pm 0.6 ; 0.8 \mathrm{~mm}, 1.9 \pm 0.2$; $1.1 \mathrm{~mm}, 1.8 \pm 0.3$. The normal/sham mice were able to traverse significantly smaller beams than the injured mice $(p<0.05)$. The $0.5-\mathrm{mm}$ lesioned mice were able to traverse significantly smaller beams than the $0.8-$ or $1.1-\mathrm{mm}$ lesioned mice $(p<0.05)$. The $0.5-, 0.8-$, and $1.1-\mathrm{mm}$ groups had a significantly higher number of errors per trial than the nor$\mathrm{mal} / \mathrm{sham}$ group $(p<0.05)$. The $0.8-\mathrm{mm}$ group could not successfully complete the task (i.e., traverse a beam $\leq 2 \mathrm{~cm}$ ) until $3 \mathrm{dpi}$, while the 1.1-mm group could not successfully complete the task until $7 \mathrm{dpi}$. The 1.4- and 1.6-mm (Tx) groups were never able to complete this task; thus they were not included in this analysis. The 0.5-, 0.8-, and 1.1-mm injury groups showed a significant difference in their pattern of task performance over the course of the study $\left(\chi^{2}=19.4, \mathrm{df}=4\right.$, $p=0.001$; chi-square analysis). The terminal scores for each of the experimental groups significantly correlated with their terminal BOS measurements $\left(r^{2}=0.89\right)$, and the amount of spared tissue in the ventral portion of the spinal cord $\left(\mathrm{r}^{2}=0.84\right)$.

\section{Subscore attribute assessments detect differences in the recovery of fine details of locomotion}

Plantar stepping. The normal/sham and $0.5-\mathrm{mm}$ groups showed no significant change in plantar stepping scores over time (Supplementary Figure 1A), nor were they ever signifi- cantly different from each other. The 0.8- and 1.1-mm groups showed significant increases in their ability to plantar step consistently over the course of the study. By $42 \mathrm{dpi}$, none of the groups were significantly different. The consistency of plantar stepping seen in the $0.5-, 0.8-$, and $1.1-\mathrm{mm}$ groups over time (Supplementary Figure 1A) correlated with the increase in the beam scores over time (Supplementary Table 4; $0.5 \mathrm{~mm}$, $\left.\mathrm{r}^{2}=0.64 ; 0.8 \mathrm{~mm}, \mathrm{r}^{2}=0.76 ; 1.1 \mathrm{~mm}, \mathrm{r}^{2}=0.95\right)$. The subscores for plantar stepping in the 0.8 - and $1.1-\mathrm{mm}$ groups also showed a significant correlation with their recovery of the toe spread reflex over the course of the study (Supplementary Table $4 ; 0.8 \mathrm{~mm}, \mathrm{r}^{2}=0.89 ; 1.1 \mathrm{~mm}, \mathrm{r}^{2}=0.82$ ). The terminal (42 dpi) plantar stepping consistency exhibited by the animals in each of the experimental groups significantly correlated with the amount of ventral spared tissue for each group (Table $1 ; \mathrm{r}^{2}=0.56$ ).

Coordination. The normal/sham and $0.5-\mathrm{mm}$ groups showed no significant change in their coordination over the course of the study (Supplementary Figure 1B). By $42 \mathrm{dpi}$, the normal/sham and $0.5-\mathrm{mm}$ groups' coordination was significantly better than that in the 0.8-, 1.1-, and 1.4-mm groups. The 0.8- and 1.1-mm groups showed significant improvement in interlimb coordination over the duration of the study. The increasing subscores for coordination in the 0.8 - and $1.1-\mathrm{mm}$ groups over the course of the study significantly correlated with the increase in their RI (Fig. 4D; $0.8 \mathrm{~mm}, \mathrm{r}^{2}=0.98$; $\left.1.1 \mathrm{~mm}, \mathrm{r}^{2}=0.43\right)$. The terminal level of coordination for all the experimental groups showed a significant correlation with the amount of ventrally spared tissue (Table $1 ; \mathrm{r}^{2}=0.85$ ) and the average stride length during locomotion (Fig. 4A; $\left.\mathrm{r}^{2}=0.65\right)$.

Paw position. The normal/sham mice walked with their hindpaws parallel to their body axis at initial contact and liftoff, and exhibited no predominance of hindpaw rotation during over-ground locomotion. The $0.5-$ and $0.8-\mathrm{mm}$ groups demonstrated a significant change in the paw position over time (Supplementary Figure 1C). The 1.1-mm group showed apparent improvement, but it was not significant. The $1.4-\mathrm{mm}$ group did not show significant improvement in the position of the paws over the course of this study. The improvements seen in the 0.5-, 0.8-, and 1.1-mm groups significantly correlated with their ability to traverse a smaller beam with fewer mistakes over the course of the study (increased beam score, Supplementary Table 4; $0.5 \mathrm{~mm}, \mathrm{r}^{2}=0.84 ; 0.8 \mathrm{~mm}, \mathrm{r}^{2}=0.74$; $\left.1.1 \mathrm{~mm}, \mathrm{r}^{2}=0.87\right)$. The $0.5-, 0.8-$, and $1.1-\mathrm{mm}$ groups' improvement in paw position over time also significantly correlated with the reduction in the number of toe drags/step cycle (Fig. $4 \mathrm{E} ; \mathrm{r}^{2}=0.72, \mathrm{r}^{2}=0.75$ and $\mathrm{r}^{2}=0.90$, respectively).

Trunk stability. The normal/sham and $0.5-\mathrm{mm}$ groups showed no significant change in their trunk stability (Supplementary Figure 1D). The trunk stability of the 0.8- and $1.1-\mathrm{mm}$ groups was significantly better by $42 \mathrm{dpi}$. The improvements in trunk stability seen in the $0.8-$ and $1.1-\mathrm{mm}$ groups significantly correlated with their ability to score higher on the beam walk test (Supplementary Table 4; $0.8 \mathrm{~mm}$, $\left.\mathrm{r}^{2}=0.82 ; 1.1 \mathrm{~mm}, \mathrm{r}^{2}=0.99\right)$. The amount of trunk stability seen in each of the experimental groups at $42 \mathrm{dpi}$ correlated with the amount of spared tissue in the ventral part of the spinal cord (Table $1 ; \mathrm{r}^{2}=0.93$ ), the average stride lengths 

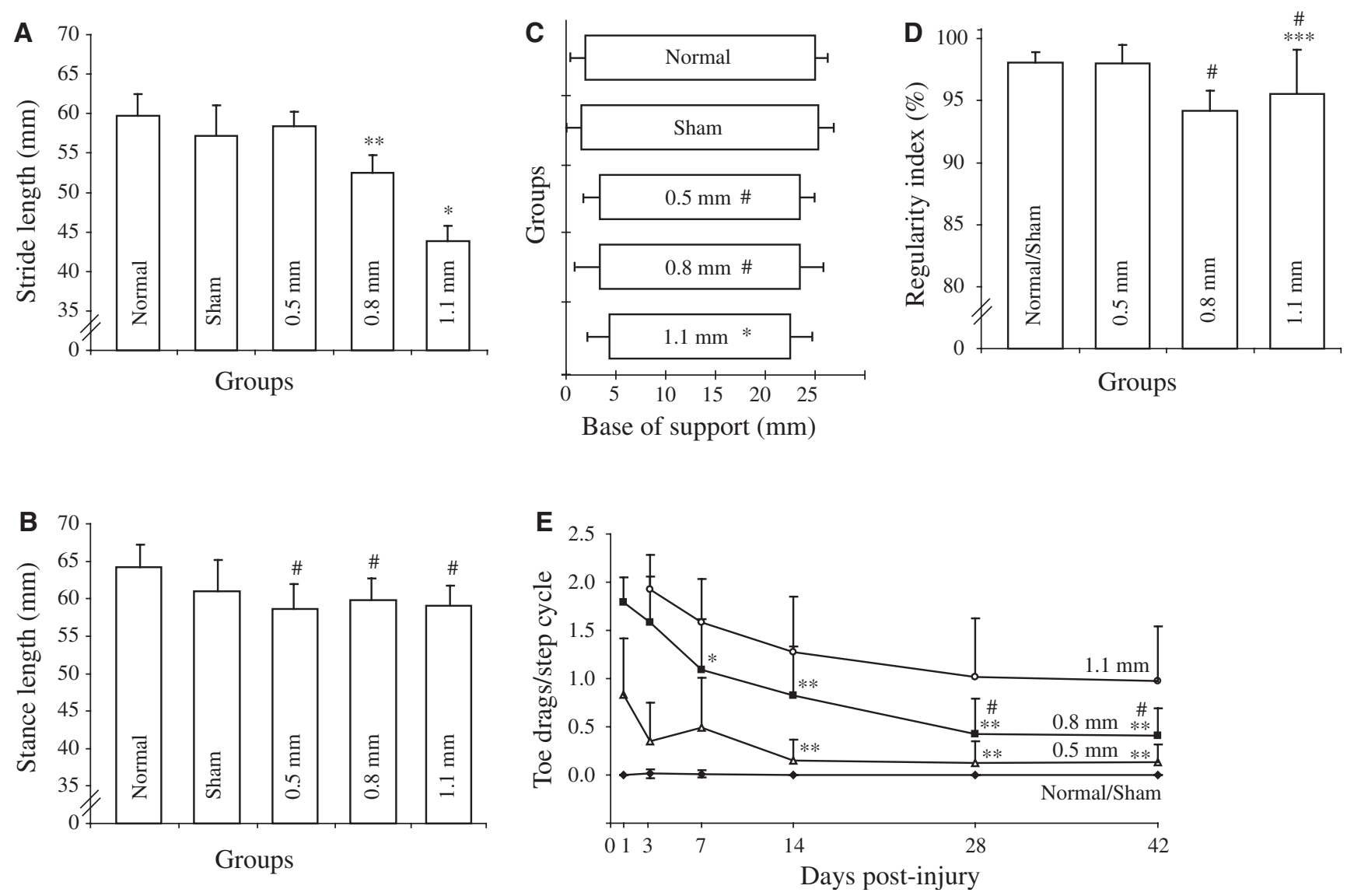

FIG. 4. Footprint analysis. (A) Stride length. The $0.8-\mathrm{mm}$ group's stride lengths were significantly shorter $\left({ }^{* *}\right)$ than the normal, sham $(p<0.01)$, and 0.5-mm groups $(p<0.05 ; \mathrm{n}=5-6)$. The 1.1-mm group's stride lengths were significantly shorter than those of all other groups $\left({ }^{*} p<0.05\right)$. (B) Stance length. The 0.5-, 0.8-, and 1.1-mm groups' stances were significantly shorter compared to the normal group (\#p<0.05; $\mathrm{n}=5-6)$. (C) Base of support (BOS). The 0.5-, 0.8- (\#p <0.05), and 1.1-mm $\left({ }^{*} p<0.01\right)$ groups' BOS were significantly smaller compared to the normal and sham groups. (D) Regularity index (RI). The $0.8-\mathrm{mm}$ group had significantly lower stepping regularity $(\%)$ than the normal/sham and $0.5-\mathrm{mm}$ groups $(\# p<0.05)$. The $1.1-\mathrm{mm}$ group's average was significantly lower than that of the normal/sham group $(* * *<0.001)$ and the 0.5 -mm group $(\# p<0.05)$. (E) Toe drags/step cycle. At 14, 28, and $42 \mathrm{dpi}$, the $0.5-\mathrm{mm}$ group showed a significant reduction in the number of toe drags/cycle than at $1 \mathrm{dpi}\left({ }^{* *} p<0.01 ; \mathrm{n}=7-13\right)$. The $0.8-\mathrm{mm}$ group at $7(\# p<0.05), 14,28$, and $42 \mathrm{dpi}\left({ }^{* *} p<0.01\right)$ showed significant reductions in the average numbers of toe drags/cycle compared to $1 \mathrm{dpi}(\mathrm{n}=7-11)$. The $28-$ and 42 -dpi averages were also significantly lower than the number of toe drags/cycle at $7 \mathrm{dpi}\left({ }^{*} p<0.05\right)$. The $1.1-\mathrm{mm}$ group showed no significant change in the number of toe drags/cycle over the course of the study.

during locomotion (Fig. 4A; $\mathrm{r}^{2}=0.91$ ), and the BOS (Fig. 4C; $\left.r^{2}=0.94\right)$ for each group.

Tail position. The 0.5 - and 0.8 -mm groups' scores for tail position rose significantly (Supplementary Figure 1E). The 1.1-mm group never showed a significant change in their tail position over time. The change in the tail position in the 0.5-, $0.8-$, and 1.1-mm groups over time significantly correlated with the improvements in their scores over time on the beam test (Supplementary Table $4 ; r^{2}=0.77, r^{2}=0.47$, and $r^{2}=0.92$, respectively). The tail position of all the animals at the termination of the study correlated with the amount of ventral spared tissue (Table $1 ; \mathrm{r}^{2}=0.60$ ).

\section{Footprint analysis shows significant deficits in stepping parameters, accompanied by some recovery}

Stride length. The 0.8- and 1.1- mm groups had significant reductions in their average stride lengths during stepping compared to the normal group (Fig. 4A; $12.1 \%$ and $26.7 \%$, respectively). The average stride lengths for each of the groups at $42 \mathrm{dpi}$ significantly correlated with the amount of spared tissue in the ventral portion of the cord $\left(\mathrm{r}^{2}=0.75\right)$.

Stance length. The 0.5-, 0.8-, and 1.1-mm groups had significant reductions in their average stance lengths during stepping (Fig. 4B; 8.7\%, 6.8\%, and 9.9\% from normal, respectively). The average stance lengths for each of the groups at 42 dpi significantly correlated with the amount of ventral spared tissue $\left(r^{2}=0.61\right)$.

Base of support. The hindlimb BOS in the 0.5-, 0.8-, and 1.1$\mathrm{mm}$ groups was significantly reduced compared to the normal and sham groups (Fig. 4C; 13\%, 12.8\%, and 21.2\%, respectively). There was a significant correlation between the lesion depth and the average BOS for these three groups $\left(r^{2}=0.74\right)$. 
Regularity index. The $0.8-$ and 1.1-mm groups had significantly lower stepping regularity (or \% interlimb coordination) than normal (Fig. 4D; 3.6\% and 3.1\%, respectively).

Toe drag. The 0.5- and 0.8-mm groups showed significant reductions in the number of toe drags/step cycle over the course of the study (Fig. 4E). The 1.1-mm injured animals were not able to perform the footprint test at $1 \mathrm{dpi}$; thus their first day of assessment was $3 \mathrm{dpi}$ (Supplementary Table 5 and Fig. 4E) and showed no significant change in the number of toe drags/cycle over the course of the study (Fig. 4E).

The amount of functional recovery of toe clearance for each group at the termination of the study was determined by converting the number of toe drags/cycle to a percentage, with 2 toe drags/step cycle being $0 \%$ recovery. The percentage of functional recovery at $42 \mathrm{dpi}$ for each of the experimental groups was as follows: normal/sham controls, $99.8 \pm 1.1 \%$; $0.5 \mathrm{~mm} ， \quad 93.4 \pm 9.1 \%$; $\quad 0.8 \mathrm{~mm} ， \quad 79.7 \pm 14.4 \%$ ； $1.1 \mathrm{~mm}$ ， $51.3 \pm 28.3 \%$. The normal/sham, $0.5-$, and $0.8-\mathrm{mm}$ groups showed significantly greater recovery of toe clearance $(\%)$ than the $1.1-\mathrm{mm}$ group $(p<0.01)$. The $0.5-\mathrm{mm}$ group was not significantly different from the normal/sham group; however, the 0.8 -mm group did show significantly lower recovery than the normal/sham group $(p<0.05)$, but was not significantly less than the 0.5 -mm group.

Hindlimb coordination (right versus left). An assessment of right-left coordination of the hindlimbs showed no significant differences between the groups for either stride or stance. However, there was a significant correlation across the groups in the amount of variance for both the stride and stance (stride, $\mathrm{r}^{2}=0.75$; stance, $\mathrm{r}^{2}=0.85$ ). The CoVs for each group's stride measurements are as follows: normal, $0.63 \pm 0.41$; sham, $0.96 \pm 0.76 ; 0.5 \mathrm{~mm}, 1.25 \pm 1.25 ; 0.8 \mathrm{~mm}$, $1.01 \pm 0.90$. The CoVs for the stance measurements are: normal, $1.21 \pm 1.29$; sham, $1.83 \pm 1.16 ; 0.5 \mathrm{~mm}, 1.58 \pm 1.63$; $0.8 \mathrm{~mm}, 2.17 \pm 1.83 ; 1.1 \mathrm{~mm}, 2.70 \pm 2.20$. The variation in the stride and stance length measurements increased with increasing severity of the injury. The stride variation also correlates with the reduction in the $\mathrm{RI}\left(\mathrm{r}^{2}=0.823\right)$.

\section{Toe spread reflex test detects deficits in the hindlimb reflex responses with recovery over time}

Neither the normal, sham, or 0.5-mm groups showed a significant change in their response scores over the course of the study (Supplementary Table 6), nor were they ever significantly different from each other. The $0.8-, 1.1-$, and $1.4-\mathrm{mm}$ groups showed significant recovery of their reflex response over the course of the study, and showed significant differences in their responses from each other at certain time points. The reflex scores for each of the groups at 42 dpi (Supplementary Table 6) significantly correlated with the amount of spared tissue (Table $1 ; \mathrm{r}^{2}=0.85$ ).

\section{Hargreaves' noxious thermal stimulus test detects response deficits in the injury groups}

A normal mouse will respond to a noxious thermal laser stimulus in $2.29 \pm 0.71 \mathrm{sec}$ for forepaws, and $2.81 \pm 0.89 \mathrm{sec}$ for hindpaws (data not shown). The normal, 0.5-, 0.8- $(p<0.001)$, and 1.1-mm $(p<0.05)$ groups all show significant differences in the response times between the forepaws and hindpaws $(\mathrm{n}=60-94)$. The 1.4-mm lesioned mice responded in a reverse fashion: the forepaw response times were significantly higher than the hindpaw response times $(p<0.001 ; \mathrm{n}=42)$.

The average forepaw responses of the 1.4-mm group were significantly slower than those of any of the other groups (Fig. 5). The average hindpaw responses of the 0.8-, 1.1-, and 1.4$\mathrm{mm}$ groups showed significant differences. The average hindpaw response times for each of the groups correlated with the amount of spared tissue ventral to the lesion (Table 1; $\left.\mathrm{r}^{2}=0.54\right)$.

\section{tcMMEP recordings demonstrate a reduction of the signal amplitude in the 1.1- and 1.4- $\mathrm{mm}$ lesioned animals}

The amplitudes of the tcMMEP recordings from the normal, 0.5-, and 0.8-mm groups were significantly greater than those from the 1.1- and 1.4-mm groups (Fig. 6). There was no significant difference in the average latencies of the signals between any of the experimental groups (data not shown). We recorded positive tcMMEP responses from all of the mice in the normal, 0.5-, and 0.8-mm groups (100\%). The 1.1-mm group showed a gradual loss of the signal. The decreasing signal occurrence frequency for the 1.1-mm group correlated with the number of days following injury $\left(\mathrm{r}^{2}=0.34\right)$. At 3 and 7 dpi we recorded signals in $100 \%$ of the hindlimbs stimulated; however, by 42 dpi we observed signals in $83.3 \%$ of the hindlimbs stimulated (data not shown). In the 1.4-mm group,

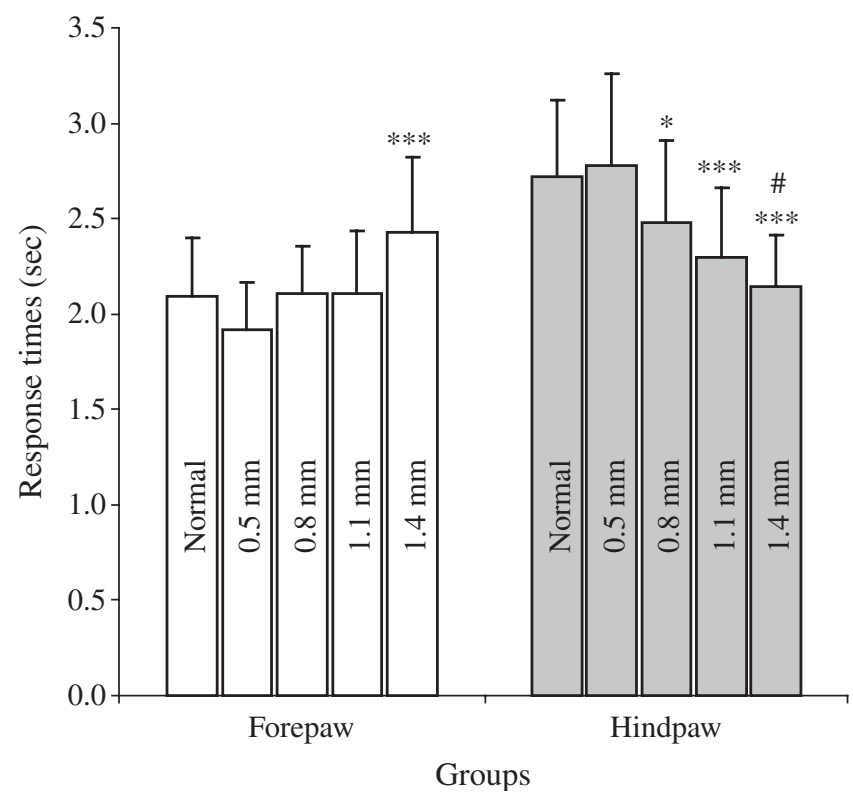

FIG. 5. Hargreaves' noxious thermal stimulus. The average forepaw responses of the 1.4-mm group were significantly faster than those of the other groups $\left({ }^{* *} p<0.001 ; \mathrm{n}=31-48\right)$. The hindpaw response times of the $0.8-\mathrm{mm}$ group were significantly less than the response times of the normal and 0.5 -mm groups $\left({ }^{*} p<0.05\right)$. The 1.1 - and 1.4-mm groups' average response times were significantly less than those of the normal and 0.5 -mm groups $\left({ }^{* * *} p<0.001\right)$. The 1.4-mm group also responded significantly slower than the $0.8-\mathrm{mm}$ group $(\# p=0.003)$. 


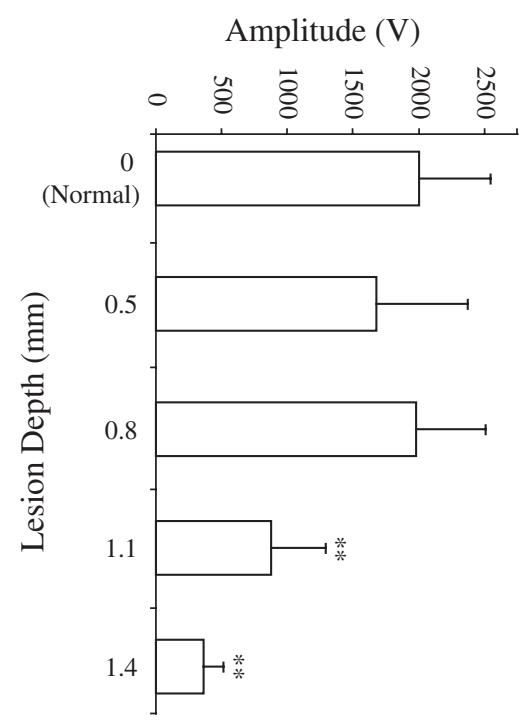

Waveforms
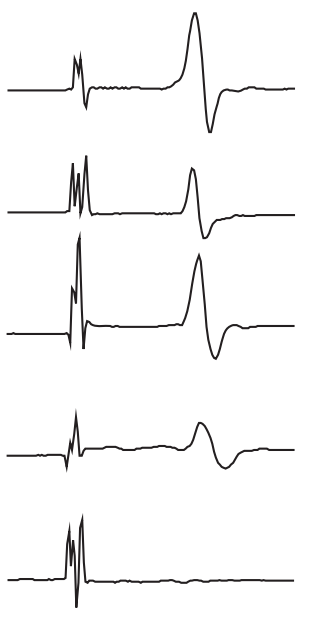

FIG. 6. Transcranial magnetic motor-evoked potentials. The amplitudes of the tcMMEP recordings from the normal, $0.5-$, and $0.8-\mathrm{mm}$ groups were significantly greater than those of the 1.1- and 1.4-mm groups $\left({ }^{* *} p<0.01 ; \mathrm{n}=7-30\right)$. Representative average amplitude waveforms are shown for each injury level. The normal, 0.5 , and $0.8 \mathrm{~mm}$ groups' amplitudes were not significantly different from each other.

there was a gradual recovery of the signal following stimulation. The increasing signal occurrence frequency for the 1.4-mm group correlated with the number of days following injury $\left(r^{2}=0.59\right)$. At $3 \mathrm{dpi}$, we got no responses in any of the 1.4-mm lesioned mice, but by $7 \mathrm{dpi}$ we recorded signals in $21.4 \%$ of the hindlimbs tested; by $42 \mathrm{dpi}$, we got recordings from 5 out of the 14 hindlimbs tested ( $35.7 \%$; data not shown).

\section{CTB and BDA tracings show disruption of ascending and descending fibers}

BDA injections into the sensorimotor cortex label descending CST axons (Zhang et al., 2004). Our results confirm that a lesion depth of at least $0.5 \mathrm{~mm}$ (Fig. 7, left panel) is sufficient to sever the fibers of the CST in the ventral portion of the dorsal columns. No spontaneous regeneration of the CST fibers was observed within or across the lesion for any of the mice in the various injury groups at 8 weeks following injury.
Cholera toxin binds to the GM1 ganglioside on the plasma membrane of neurons and taken into the axon by endocytosis (Trojanowski et al., 1982; Wan et al., 1982). When injected into the sciatic nerve, CTB is anterogradely transported through the dorsal root ganglia and labels large, myelinated $\mathrm{A} \beta$-axons (Grant, 1993; Maxwell and Rethelyi, 1987; White and Kocsis, 2002; Willis and Coggeshall, 1991). Bilateral CTB labeling demonstrated a disruption of these fibers in even the mildest injury group (0.5-mm lesion; Fig. 7, right panel). All of the more severely injured mice showed the same disruption of CTB labeling in the posterior columns (data not shown). These results confirmed that a lesion depth of at least $0.5 \mathrm{~mm}$ disrupted this population of sensory fibers. We did not observe any of these severed CTB-labeled axons crossing the lesion.

\section{Discussion}

In this study, we describe a novel injury device, the LISAVibraknife, which can produce a precise SCI. Our surgical techniques result in consistent and reproducible lesions, and our comprehensive behavioral analysis identified specific sensory, sensorimotor, and motor deficits along a dorsal-toventral gradient.

Stabilization of the spinal column is vital to SCI models. This was previously emphasized by Kuhn and Wrathall (1998) and Scheff and colleagues (2003), but was not experimentally documented. Our results suggest that supporting the segment at which the lesion is being induced (Fig. 1A) greatly reduces vertebral motion. Two additional advantages to the laceration model of SCI generated by the LISAVibraknife are the precise control of the lesion displacement and the elimination of accompanied contusive components at the lesion site by compression of the tissue that is often seen following microscissor lacerations (Bartholdi and Schwab, 1997). We attribute the observed reduction in the actual lesion depth compared to the desired depth seen in Table 1 to flexion or resistance in the spinal cord tissue and/or displacement of cerebrospinal fluid during the laceration procedure. One mechanical limitation of this study is the method used for determining dural contact of the blade with the spinal cord, which was visually confirmed through a dissecting microscope. An alternative may be to use an electrical circuit (Constantini and Young, 1994; Gruner, 1992; Huang and Young, 1994) or laser detection to monitor blade contact with the spinal cord (Zhang et al., 2007a).
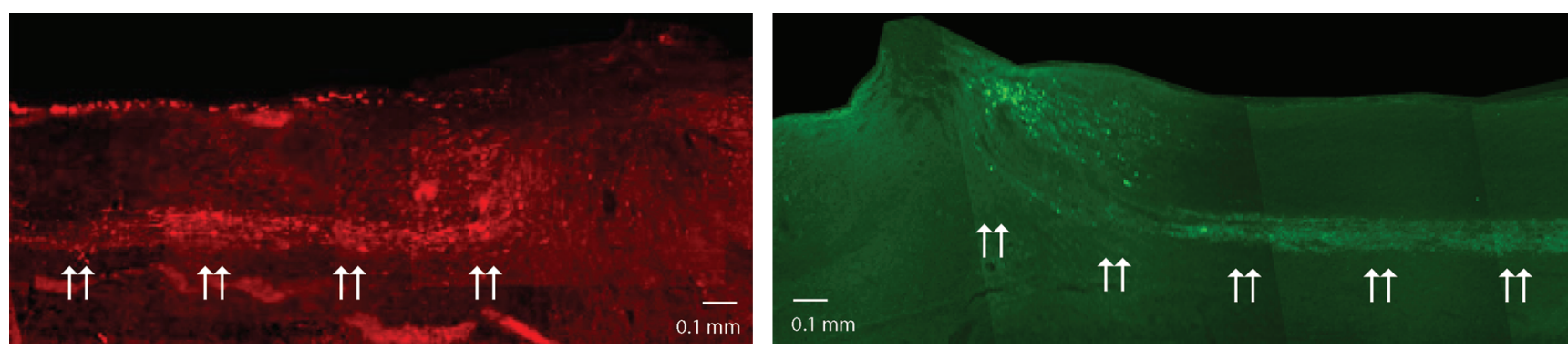

FIG. 7. Axonal tracing. The top panel shows a 0.5-mm lesioned mouse spinal cord; note the disruption of the CST fibers (BDA-labeled fibers are indicated by the arrows) at the rostral border of the lesion. No BDA labeling can be seen crossing the lesion. The bottom panel shows a 0.5- $\mathrm{mm}$ lesioned cord; note how the CTB labeling stops at the caudal edge of the lesion (arrows). Top to bottom: dorsal to ventral; left to right: rostral to caudal. 


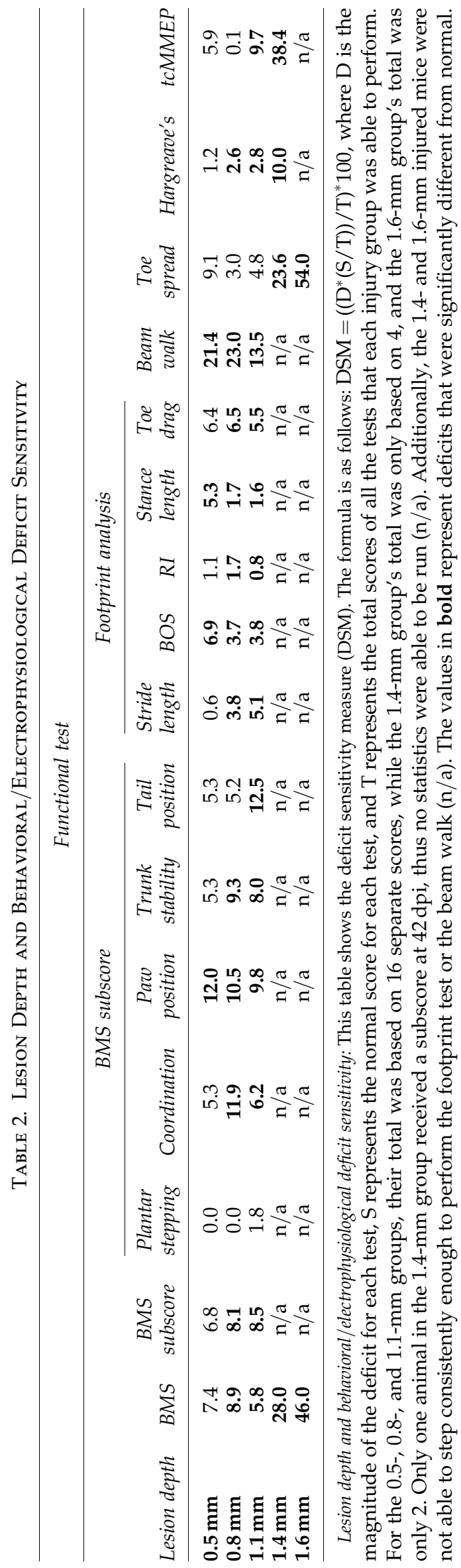

In contrast to a laceration SCI in the rat, the mouse laceration does not generate a gap between the cord stumps. At $42 \mathrm{dpi}$, the rostral-caudal extent of the lesion was minimal and there was no cavitation observed. The increased interface proximity of the two cord stumps may contribute to the elimination of cavitation in this injury model. It has been previously shown that the lesion pathology seen following SCI in mice is different compared to other rodent models of SCI (Balantine, 1978; Farooque, 2000; Inman and Steward, 2003a; Kuhn and Wrathall, 1998; Sroga et al., 2003). We anticipated that this model would exhibit a lesser degree of secondary injury by inducing less edema and tissue destruction.

A variety of tests were used (Goldberger, 1991; Metz et al., 2000; Muir and Webb, 2000) to look at specific and detailed components of motor, sensorimotor, and sensory function. They enable the detection of subtle changes in the behavior of the animals, functional differentiation of the levels of injury severity, and the establishment of temporal recovery profiles for each of the injury groups. The association of behavioral/electrophysiological deficits with our laceration lesions (Table 2) demonstrates that particular assessments are more sensitive at detecting functional loss for a particular lesion depth, and also demonstrates that different tests differentiate specific deficits. The higher the deficit sensitivity measure (DSM), the more sensitive that test was at detecting deficits for that injury level. This also depended on the number of deficits being detected. For example, in the 0.5$\mathrm{mm}$ group, the BMS detected $7.4 \%$, whereas the beam walk detected $21.4 \%$ of the total deficit. In the $1.1-\mathrm{mm}$ group, the amount of deficit detected by each of the tests is more widely and more evenly distributed. Several of the measures still stand out with large DSMs, such as paw and tail position, beam walk, and tcMMEP, thus demonstrating the importance of these measures in detecting deficits for this level of injury.

This study does not, however, give us enough information to correlate precise laceration depths with specific white matter fiber tract loss. The two fiber tracts that we did trace, show complete transection with a $0.5-\mathrm{mm}$ lesion. However, neither of these pathways carries information whose loss is detectable by the behavioral tests we performed. Further studies using anterograde and retrograde tracing of tracts involved with locomotor function (Loy et al., 2002b; Schucht et al., 2002) would be required to make more definitive conclusions about specific damage to tract(s) in relationship to deficits.

The BMS scores differentiated each group and independently verified the sensitivity of the BMS scale (Basso et al., 2006) in an alternate model of mouse SCI. Footprint analysis shows a significant reduction in the BOS in the 0.5-, 0.8-, and 1.1-mm groups. These changes may be related to damage to the propriospinal system (Kunkel-Bagden et al., 1993). This result supports previous studies that place the location of these propriospinal tracts in the dorsolateral white matter (Beaumont et al., 2006), suggesting that the loss of these axons may contribute to the reduction in the BOS.

By modifying the beam walk test used previously on rats (Kunkel-Bagden et al., 1993), we detected significant changes in the groups over time and significant differences between the groups. Even the mild 0.5-mm lesioned group exhibited significant deficits in performing this task. Therefore, the 
gradient beam walk may be an optimal approach to assess behavioral outcomes for mice that receive any type of mild SCI. A similar test, the grid walking test, has been shown to be related to propriospinal and rubrospinal pathway function (Bresnahan et al., 1987; Whishaw et al., 1992). Based on results from the beam walk test, the contribution of the rubrospinal pathway may be more significant than the propriospinal axons in the dorsolateral funiculus. The $0.5-\mathrm{mm}$ lesion should only partially damage the rubrospinal pathway (if at all), whereas the lesions below that level would completely sever all the fibers. The significant amount of functional recovery and the fact that the $0.5-\mathrm{mm}$ lesioned mice scored significantly higher than the 0.8 - or 1.1-mm groups, suggests that the spared rubrospinal pathway and dorsal lateral funiculus (DLF) are contributing to the performance of this behavioral task. In the 0.8- and 1.1-mm groups, where the rubrospinal pathway has been completely severed, we see some recovery of function, suggesting a potential contribution to performance of this task from the spared propriospinal and DLF pathways.

Results from the Hargreaves' test suggest that an animal with a lesion depth greater than $0.5 \mathrm{~mm}$ will show increased thermal sensitivity in the hindpaws due to a gradual dorsalventral loss of spinothalamic tract fibers (Willis and Westlund, 1997). However, the reduced response time seen in the forepaws of the 1.4-mm group was unexpected. A possible explanation for this may be the increased reliance on the forepaws in these animals for support of their body due to the degree of hindlimb paralysis.

The tcMMEP results replicate in the mouse previous work done in the rat showing a correlation between loss of the ventrolateral funiculus and the tcMMEP response (Cao et al., 2005; Loy et al., 2002a,b). The small-amplitude responses detected in the 1.4-mm lesioned mice may be due to a small number of spared fibers in the ventral-most part of the ventrolateral funiculus.

The varied degrees of deficit and recovery seen in this study suggest spinal plasticity below the level of the lesion contributing to the recovery of hindlimb motor and sensory function. The sprouting of sensory fibers below the level of a spinal transection has been shown in previous studies (Goldberger et al., 1993; Helgren and Goldberger, 1993; Krenz and Weaver, 1998; Wong et al., 2000). A possible mechanism for this spontaneous recovery of function may be a reactive reorganization of the circuitry below the lesion, thus compensating for the loss of ascending and descending inputs. In future studies, we may be able to increase the amount of functional recovery seen following thoracic SCI by promoting sensory fiber sprouting.

In summary, we demonstrate that the LISA-Vibraknife can be used in future studies requiring precise, consistent, reproducible laceration SCIs. Importantly, we conclude that the combination of specific outcome measures can optimally detect sensory and motor functional deficits for particular SCI severities.

\section{Acknowledgments}

This work was supported by the Kentucky Spinal Cord and Head Injury Research Trust (KSCHIRT), Commonwealth of Kentucky Challenge for Excellence, Norton Healthcare, and RR15576.

\section{Author Disclosure Statement}

No conflicting financial interests exist.

\section{References}

Allen, A.R. (1911). Surgery of experimental lesion of spinal cord equivalent to crush injury of fracture dislocation of spinal column: a preliminary report. JAMA 57, 878-880.

Balantine, J.D. (1978). Pathology of experimental spinal cord trauma. I. The necrotic lesion as a function of vascular injury. Lab. Invest. 39, 236-253.

Bartholdi, D., and Schwab, M.E. (1997). Expression of pro-inflammatory cytokine and chemokine mRNA upon experimental spinal cord injury in mouse: an in situ hybridization study. Euro. J. Neurosci. 9, 1422-1438.

Basso, D.M., and Fisher, L.C. (2003) The Basso Mouse Scale for Locomotion (BMS) is a more sensitive indicator of recovery than the BBB scale in mice with spinal cord injury. In Society for Neuroscience Abstract.

Basso, D.M., Fisher, L.C., Anderson, A.J., Jakeman, L.B., McTigue, D.M., and Popovich, P.G. (2006). Basso Mouse Scale for locomotion detects differences in recovery after spinal cord injury in five common mouse strains. J. Neurotrauma 23, 635-659.

Beattie, M.S., Stokes, B.T., and Bresnahan, J.C. (1988). Experimental spinal cord injury: strategies for acute and chronic intervention based on anatomic, physiologic, and behavioral studies, in: Pharmacological Approaches to the Treatment of Brain and Spinal Cord Injury. D. Stein, and B. Sabel (eds), Plenum Publishing: New York, pps. 43-74.

Beaumont, E., Onifer, S.M., Reed, W.R., and Magnuson, D.S.K. (2006). Magnetically evoked inter-enlargement response: An assessment of ascending propriospinal fibers following spinal cord injury. Exp. Neurol. 201, 428-440.

Blight, A.R., and Decrescito, V. (1986). Morphometric analysis of experimental spinal cord injury in the cat: The relation of injury intensity to survival of myelinated axons. Neuroscience 19, 321-341.

Blight, A.R. (1983). Cellular morphology of chronic spinal cord injury in the cat: analysis of myelinated axons by line-sampling. Neuroscience 10, 521-543.

Bresnahan, J.C., Beattie, M.S., Todd, F.D.I., and Noyes, D.H. (1987). A behavioral and anatomical analysis of spinal cord injury produced by a feedback-controlled impaction device. Exp. Neurol. 95, 548-570.

Bresnahan, J.C., King, J.S., Martin, G.F., and Yashon, D. (1976). A neuroanatomical analysis of spinal cord injury in the rhesus monkey (Macaca mulatta). J. Neurol. Sci. 28, 521-542.

Bunge, R.P., Puckett, W.R., Becerra, J.L., Marcillo, A., and Quencer, R.M. (1993). Observations on the pathology of human spinal cord injury: a review and classification of 22 new cases with details from a case of chronic cord compression with extensive focal demyelination, in: Advances in Neurology. F.J. Seil (ed), Raven Press: New York, pps. 75-89.

Cao, Q., Zhang, Y.P., Iannotti, C., Devries, W.H., Xu, X.-M., Shields, C.B., and Whittemore, S.R. (2005). Functional and electrophysiological changes after graded traumatic spinal cord injury in adult rat. Exp. Neurol. 2005 (Suppl. 1), S3-S16.

Constantini, S., and Young, W. (1994). The effects of methylprednisolone and the ganglioside GM1 on acute spinal cord injury in rats. J. Neurosurg. 80, 97-111.

De Medinacelli, L., Freed, W.J., and Wyatt, R.J. (1982). An index of the functional condition of rat sciatic nerve based on measurements made from walking tracks. Exp. Neurol. 77, 634-643. 
Eidelberg, E., Nguyen, L.H., and Deza, L.D. (1986). Recovery of locomotor function after hemisection of the spinal cord of cats. Brain Res. Bull. 16, 507-515.

Engesser-Cesar, C., Anderson, A.J., Basso, D.M., Edgerton, V.R., and Cotman, C.W. (2005). Voluntary wheel running improves recovery from a moderate spinal cord injury. J. Neurotrauma 22, 157-171.

Farooque, M. (2000). Spinal cord compression injury in the mouse: presentation of a model including assessment of motor dysfunction. Acta Neuropathology 100, 13-22.

Fehlings, M.G., and Tator, C.H. (1988). A review of experimental models of acute spinal cord injury, in: Spinal Cord Dysfunction: Assessment. L. Illis (ed), Oxford University Press: New York, pps. 3-33.

Fehlings, M.G., and Tator, C.H. (1995). The relationship among the severity of spinal cord injury, residual neurological function, axon counts, and counts of retrogradely labeled neurons after experimental spinal cord injury. Exp. Neurol. 132, 220228.

Fiore, C., Inman, D.M., Hirose, S., Noble, L.J., Igarashi, T., and Compagnone, N.A. (2004). Treatment with the neurosteroid dehydroepiandrosterone (DHEA) promotes recovery of motor behavior after moderate contusive SCI in the mouse. J. Neurosci. Res. 75, 391-400.

Fujiki, M., Zhang, Z., Guth, L., and Steward, O. (1996). Genetic influences on cellular reactions to spinal cord injury: activation of macrophages/microglia and astrocytes is delayed in mice carrying a mutation (WldS) that causes delayed Wallerian degeneration. J. Comp. Neurol. 371, 469-484.

Ghasemlou, N., Kerr, B.J., and David, S. (2005). Tissue displacement and impact force are important contributors to outcome after spinal cord contusion injury. Exp. Neurol. 196, 9-17.

Goldberger, M.E., Murray, M., and Tessler, A. (1993). Sprouting and regeneration in the spinal cord. Their roles in recovery of function after spinal cord injury, in: Neuroregeneration. A. Gorio (ed), Raven: New York, pps. 241-264.

Goldberger, M.E. (1991). The use of behavioral methods to predict spinal cord plasticity. J. Restor. Neurol. Neurosci. 2, 339-350.

Grant, G. (1993). Projection patterns of primary sensory neurons studied by transganglionic methods: Somatotopy and targetrelated organization. Brain Res. Bull. 30, 199-208.

Gruner, J.A. (1992). A monitored contusion model of spinal cord injury in the rat. J. Neurotrauma 9, 123-136.

Hamers, F.P.T., Lankhorst, A.J., Jan Van Laar, T., Veldhuis, W.B., and Gispen, W.H. (2001). Automated quantitative gait analysis during overground locomotion in the rat: Its application to spinal cord contusion and transection injuries. J. Neurotrauma 18, 187-201.

Hargreaves, K., Dubner, R., Brown, F., Flores, C., and Joris, J. (1988). A new and sensitive method for measuring thermal nociception in cutaneous hyperalgesia. Pain 32, 77-88.

Helgren, M.E., and Goldberger, M.E. (1993). The recovery of postural reflexes and locomotion following low thoracic hemisection in adult cats involves compensation by undamaged primary afferent pathways. Exp. Neurol. 123, 17-34.

Huang, P.P., and Young, W. (1994). The effects of arterial blood gas values on lesion volumes in a graded rat spinal cord contusion model. J. Neurotrauma 11, 547-562.

Inman, D.M., and Steward, O. (2003b). Ascending sensory, but not other long-tract axons, regenerate into the connective tissue matrix that forms at the site of a spinal cord injury in mice. J. Comp. Neurol. 462, 431-449.
Inman, D.M., and Steward, O. (2003a). Physical size does not determine the unique histopathological response seen in the injured mouse spinal cord. J. Neurotrauma 20, 33-42.

Inman, D.M., Guth, L., and Steward, O. (2002). Genetic influences on secondary degeneration and wound healing following spinal cord injury in various strains of mice. J. Comp. Neurol. 451, 225-235.

Jacob, J.E., Pniak, A., Weaver, L.C., and Brown, A. (2001). Autonomic dysreflexia in a mouse model of spinal cord injury. Neuroscience 108, 687-693.

Jakeman, L.B., Guan, Z., Wei, P., Ponnappan, R., Dzwonczyk, R., Popovich, P.G., and Stokes, B.T. (2000). Traumatic spinal cord injury produced by controlled contusion in the mouse. J. Neurotrauma 17, 299-319.

Joshi, M., and Fehlings, M.G. (2002b). Development and characterization of a novel, graded model of clip compressive spinal cord injury in the mouse: Part 1. Clip design, behavioral outcomes, and histopathology. J. Neurotrauma 19, 175-190.

Joshi, M., and Fehlings, M.G. (2002a). Development and characterization of a novel, graded model of clip compressive spinal cord injury in the mouse: Part 2. Relationships between axonal tracts, residual tissue and locomotor recovery. J. Neurotrauma $19,191-203$.

Kakulas, B.A. (1999). A review of neuropathology of human spinal cord injury with emphasis on special features. J. Spinal Cord Med. 22, 119-124.

Krenz, N.R., and Weaver, L.C. (1998). Sprouting of primary afferent fibers after spinal cord transection in the rat. Neuroscience $85,443-458$.

Kuhn, P.L., and Wrathall, J.R. (1998). A mouse model of graded contusive spinal cord injury. J. Neurotrauma 15, 125-140.

Kunkel-Bagden, E., Dai, H.N., and Bregman, B.S. (1993). Methods to assess the development and recovery of locomotor function after spinal cord injury in rats. Exp. Neurol. 119, 153164.

Loy, D.N., Magnuson, D.S.K., Zhang, Y.P., Onifer, S.M., Mills, M.D., Cao, Q., Darnall, J.B., Fajardo, L.C., Burke, D.A., and Whittemore, S.R. (2002a). Functional redundancy of ventral spinal locomotor pathways. J. Neurosci. 22, 315-323.

Loy, D.N., Talbott, J.F., Onifer, S.M., Mills, M.D., Burke, D.A., Dennison, J.B., Fajardo, L.C., Magnuson, D.S.K., and Whittemore, S.R. (2002b). Both dorsal and ventral spinal cord pathways contribute to overground locomotion in the adult rat. Exp. Neurol. 177, 575-580.

Ma, M., Basso, D.M., Walters, P., Strokes, B.T., and Jakeman, L.B. (2001). Behavioral and histological outcomes following graded spinal cord contusion injury in the C57Bl/6 mouse. Exp. Neurol. 169, 239-254.

Maxwell, D., and Rethelyi, R. (1987). Ultrastructure and synaptic connections of cutaneous afferent fibres in the spinal cord. Trends Neurosci. 10, 117-122.

Metz, G.A.S., Merkler, D., Dietz, V., Schwab, M.E., and Fouad, K. (2000). Efficient testing of motor function in spinal cord injured rats. J. Neurotrauma 17, 1-17.

Muir, G.D., and Webb, A.A. (2000). Assessment of behavioral recovery following spinal cord injury in rats. Euro. J. Neurosci. 12, 3079-3086.

Noble, L.J., and Wrathall, J.R. (1985). Spinal cord contusion in the rat: morphometric analyses of alterations in the spinal cord. Exp. Neurol. 88, 135-149.

Plemel, J.R., Duncan, G., Chen, K.W., Shannon, C., Park, S., Sparling, J.S., and Tetzlaff, W. (2008). A graded forceps crush spinal cord injury model in mice. J. Neurotrauma 25, 350370 . 
Ramer, L.M., Ramer, M.S., and Steeves, J.D. (2005). Setting the stage for functional repair of spinal cord injuries: a cast of thousands. Spinal Cord 43, 134-161.

Scheff, S.W., Rabchevsky, A.G., Fugaccia, I., Main, J.A., Lumpp, J., and James, E. (2003). Experimental modeling of spinal cord injury: characterization of a force-defined injury device. J. Neurotrauma 20, 179-193.

Schucht, P., Raineteau, O., Schwab, M.E., and Fouad, K. (2002). Anatomical correlates of locomotor recovery following dorsal and ventral lesions of the rat spinal cord. Exp. Neurol. 176, 143-153.

Schwab, J.M., Brechtel, K., Mueller, C.-A., Failli, V., Kaps, H.-P., Tuli, S.K., and Schluesener, H.J. (2006). Experimental strategies to promote spinal cord regeneration-an integrative perspective. Prog. Neurobiol. 78, 91-116.

Seitz, A., Aglow, E., and Heber-Katz, E. (2002). Recovery from spinal cord injury: A new transection model in the C57Bl/6 mouse. J. Neurosci. Res. 67, 337-345.

Seki, T., Hida, K., Tada, M., Koyanagi, I., and Iwasaki, Y. (2002). Graded contusion model of the mouse spinal cord using a pneumatic impact device. Neurosurgery 50, 1075-1082.

Sivasankaran, R., Pei, J., Wang, K.C., Zhang, Y.P., Shields, C.B., $\mathrm{Xu}, \mathrm{X}$.-M., and He, Z. (2004). PKC mediates inhibitory effects of myelin and chondroitin sulfate proteoglycans on axonal regeneration. Nature Neurosci. 7, 261-268.

Sroga, J.M., Jones, T.B., Kigerl, K.A., McGaughy, V.M., and Popovich, P.G. (2003). Rats and mice exhibit distinct inflammatory reactions after spinal cord injury. J. Comp. Neurol. 462, 223-240.

Steward, O., Schauwecker, P.E., Guth, L., Zhang, Z., Fujiki, M., Inman, D.M., Wrathall, J.R., Kempermann, G., Gage, F.H., Saatman, K.E., Raghupathi, R., and McIntosh, T.K. (1999). Genetic approaches to neurotrauma research: opportunities and potential pitfalls of murine models. Exp. Neurol. 157, $19-42$.

Steward, O., Zheng, B., Ho, C., Anderson, K., and Tessier-Lavigne, M. (2004). The dorsolateral corticospinal tract in mice: an alternative route for corticospinal input to caudal segments following dorsal column lesions. J. Comparative Neurol. 472, 463-477.

Stokes, B.T. (1992). Experimental spinal cord injury: a dynamic and verifiable injury device. J. Neurotrauma 9, 129-134.

Taoka, Y., and Okajima, K. (1998). Spinal cord injury in the rat. Prog. Neurobiol. 56, 341-358.

Trojanowski, J.Q., Gonatas, J.O., and Gonatas, N.K. (1982). Horseradish peroxidase (HRP) conjugates of cholera toxin and lectins are more sensitive retrogradely transported markers than free HRP. Brain Res. 231, 33-50.

Wan, X.-C.S., Trojanowski, J.Q., and Gonatas, J.O. (1982). Cholera toxin and wheat germ agglutinin conjugates as neuroanatomical probes: their uptake and clearance, transganglionic and retrograde transport and sensitivity. Brain Res. 243, 215224.
Whishaw, I.Q., Pellis, S.M., and Pellis, V.C. (1992). A behavioral study of the contributions of cells and fibers of passage in the red nucleus of the rat to postural righting, skilled movements, and learning. Behav. Brain Res. 52, 29-44.

White, F.A., and Kocsis, J.D. (2002). A-fiber sprouting in spinal cord dorsal horn is attentuated by proximal nerve stump encapsulation. Exp. Neurol. 177, 385-395.

Willis, W.J., and Coggeshall, I.R. (1991). Dorsal root ganglion cells and their processes, in: Sensory Mechanisms of the Spinal Cord. Plenum: New York, pps. 49-78.

Willis, W.J., and Westlund, K.N. (1997). Neuroanatomy of the pain system and of the pathways that modulate pain. J. Clin. Neurophysiol. 14, 2-31.

Wong, S.T., Atkinson, B.A., and Weaver, L.C. (2000). Confocal microscopic analysis reveals sprouting of primary afferent fibers in rat dorsal horn after spinal cord injury. Neurosci. Lett. 296, 65-88.

Wrathall, J.R., Pettegrew, R.K., and Harvey, F. (1985). Spinal cord contusion in the rat: production of graded, reproducible, injury groups. Exp. Neurol. 88, 108-122.

Zang, D.W., and Cheema, S.S. (2003). Leukemia inhibitory factor promotes recovery of locomotor function following spinal cord injury in the mouse. J. Neurotrauma 20, 1215-1222.

Zhang, Y.P., Iannotti, C., Shields, L., Han, E., Burke, Y., Xu, D.A., and Shields, C.B. (2004). Dural closure, cord approximation, and clot removal: enhancement of tissue sparing in a novel laceration spinal cord injury model. J. Neurosurg. Spine 100, 343-352.

Zhang, Y.P., Shields, L.B.E., Zhang, Y., Pei, J., Xu, X.-M., Hoskins, R., Cai, J., Qiu, M.S., Magnuson, D.S.K., Burke, D.A., and Shields, C.B. (2007b). Use of magnetic stimulation to elicit motor evoked potentials, somatosensory evoked potentials, and H-reflexes in non-sedated rodents. J. Neurosci. Methods 165, 9-17.

Zhang, Y.P., Shields, L., Chekmenev, S., Dincman, T., Zhang, Y., Zheng, Y., Smith, R., Devries, W.H., Hu, X., Magnuson, D.S.K., Whittemore, S.R., and Shields, C.B. (2007a). Combined assessment to discriminate small functional differences following spinal cord contusion based on precise vertebral stabilization and tissue displacement. J. Neurotrauma (manuscript submitted).

Zhang, Z., Fujiki, M., Guth, L., and Steward, O. (1996). Genetic influences on cellular reactions to spinal cord injury: A wound healing response in normal mice is impaired in mice carrying a mutation (WldS) that causes delayed Wallerian degeneration. J. Comp. Neurol. 371, 485-495.

Address reprint requests to: Christopher B. Shields, M.D. University of Louisville

210 East Gray Street, Suite 1102 Louisville, KY 40202

E-mail: cbshields1@gmail.com 
